\title{
Calculation of Phase Diagrams and First-Principles Study of Germanium Impacts on Phosphorus Distribution in Czochralski Silicon
}

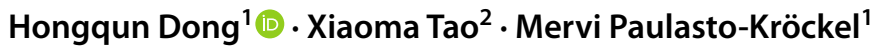

Received: 21 August 2020 / Accepted: 4 March 2021 / Published online: 21 April 2021

(c) The Author(s) 2021

\begin{abstract}
Phosphorus (P) is one of the most widely used donor dopants for fabricating a low-resistivity silicon ( $\mathrm{Si}$ ) substrate. However, its volatile nature and the relatively small equilibrium segregation coefficient in $\mathrm{Si}$ at the melting temperature of $\mathrm{Si}$ impede the efficient and effective growth of low-resistivity Czochralski (CZ) Si single crystal. The primary objective of this work is to theoretically perceive the influence of germanium co-doping on the heavily P-doped Si crystal by means of CALculation of PHase Diagrams (CALPHAD) approaches and density functional theory (DFT) calculations. Phase equilibria at the Sirich corner of the Si-Ge-P system has been thermodynamically extrapolated based on robust thermodynamic descriptions of involved binary systems, where Si-P and Ge-P have been re-assessed in this work. Phase diagram calculation results indicate that at a given $\mathrm{P}$ concentration (e.g. 0.33 at.\% P) Ge co-doping lowers the solidification temperature of the $\mathrm{Si}(\mathrm{Ge}, \mathrm{P})$ alloys, as well as the relevant equilibrium segregation coefficients of $\mathrm{P}$ in the doped Si. DFT calculations simulated the formation of (i) monovacancy in $\mathrm{Si}$ as well as (ii) solutions of $\mathrm{Si}(\mathrm{P})$ and $\mathrm{Si}(\mathrm{Ge})$ with one dopant substitutionally inserted in 64- and 216-atom Si cubic supercells. Binding energies were calculated and compared for Ge-Ge, Ge-P and P-P bonds positioning at the first nearest-neighbors ( $1 \mathrm{NN}$ ) to the third nearest-neighbors (3NN). P-P bonds have the largest bonding energy from $1 \mathrm{NN}$ to $3 \mathrm{NN}$ configurations. The climbing image nudged elastic band method (CL-NEB) was utilized to calculate the energy barriers of P $1 \mathrm{NN}$ jump in the 64-atom Si cubic supercell with/without a neighboring Ge atom. With Ge present, a higher energy barrier for P $1 \mathrm{NN}$ jump was obtained than that without involving Ge. This indicates that Ge can impede the $\mathrm{P}$ diffusion in Si matrix.
\end{abstract}

Keywords Germanium co-doping · heavily P-doped Si · equilibrium segregation coefficient · CALPHAD · density functional theory $\cdot$ formation energy

\section{Introduction}

With the ongoing trend towards multifunction and miniaturization in electronic devices, contact resistivity associated power consumption is increasingly pronounced. This, together with the demand for low on-resistance of power devices, drives the need for lowering the resistivity of

Hongqun Dong

hongqun.dong@aalto.fi

1 Department of Electrical Engineering and Automation, School of Electrical Engineering, Aalto University, PO Box 13500, 00076 Aalto, Finland

2 School of Physical Science and Technology, Guangxi University, Nanning 530004, China substrate that can then be utilized to fabricate the epitaxial structure. Phosphorus is a favorable dopant species. Despite the mature technology in Czochralski (CZ) Si growth, the growth of heavily P-doped CZ Si crystal with high yield is not without challenges. ${ }^{1}$

Basically, issues related to crystal growth are provoked by the small equilibrium distribution (segregation) coefficient $\left(K_{\text {eq }}\right)$, the highly volatile nature of $\mathrm{P}$, and the retrograde character of the $\mathrm{Si}(\mathrm{P})$ solidus. ${ }^{1-4}$ The small $K_{\text {eq }}$ results in the uneven distribution of $\mathrm{P}$ along the $\mathrm{Si}$ ingot (i.e. concentration of $\mathrm{P}$ increasing along the crystal body), thus affecting the yield of the demanding resistivity level of the CZ Si ingots. This phenomenon is marginal in lightly P-doped CZ Si since one can optimize the fabrication parameters to achieve a good balance between the enrichment of $\mathrm{P}$ at crystal/melt interface and the loss of $\mathrm{P}$ resulted from evaporation. However, the 
evaporation rate of $\mathrm{P}$ increases with increasing doping level, which leads to severe loss of $\mathrm{P}$ during melting, homogenization, and crystal pulling stages of CZ Si growth process. In addition, the retrograde $\mathrm{P}$ solubility in Si results in the non-constant $K_{\text {eq }}$ values of $\mathrm{P}$ at light and high doping levels. To precisely control the crystal growth process, the relevant $K_{\text {eq }}$ values at high P doping levels is indispensable since the widely accepted $K_{\text {eq }}$ value of 0.35 is no longer applicable to the growth of low resistivity P-doped Si crystal. Moreover, $\mathrm{P}$ atoms enter substitutionally in $\mathrm{Si}^{5-7}$ Misfit between the covalent radii of $\mathrm{P}$ and $\mathrm{Si}$ introduces the solute strain in the crystal thus generating an internal stress. ${ }^{8-10}$ According to Vegard's law, substitutional P atoms in Si generates a lattice contraction with respect to Si crystal. ${ }^{9,11,12}$ These issues give rise to potential challenges in controlling dislocation-free silicon crystal growth and fabricating good quality epitaxial layer (epi-layer). For instance, when a lightly doped ( $\mathrm{n}-$ ) epi-layer is grown on a heavily doped $(n+)$ Si substrate, the misfit dislocation can form at the substrate/epi-layer interface. ${ }^{10}$ Furthermore, the composition gradient drives the diffusion of $\mathrm{P}$ from heavily doped substrate towards the lightly doped epi-layer during subsequent processing, thus likely forming another auto-doped layer between the $n+$ substrate and the $\mathrm{n}-$ epi-layer.

Co-doping (i.e. using a third element in addition to the selected dopant) has been proposed as a solution to the aforementioned issues, such as to lower the evaporation of the volatile species, to enlarge the $K_{\text {eq }}$ value of selected dopant, to compensate for the misfit due to atomic size differences and to retard the diffusion of dopant. ${ }^{10,13}$ Germanium $(\mathrm{Ge})$ is a promising dopant in $\mathrm{Si}$ since it has the potential to control the defect formation. ${ }^{10,14}$ In this respect, $\mathrm{Ge}$ can be an electrically neutral co-dopant in P-doped Si. To explore the Ge influence on the P-doped Si crystal, investigations were performed on the carrier mobility $(\mu)$, resistivity $(\rho), K_{\mathrm{eq}}$ and process parameters of Ge-P co-doped CZ Si growth. ${ }^{10,15,16}$ The Hall-measurements on the P-doped $\mathrm{Si}_{x} \mathrm{Ge}_{1-x}(0.93<x<0.96)$ single crystal showed that when carrier concentration was higher than $10^{18}$ atoms $/ \mathrm{cm}^{3}$, the obtained $\mu$ and resistivity values were comparable to those in the P-doped Si. ${ }^{15}$ The $K_{\text {eq }}$ of $\mathrm{P}$ in $\mathrm{Si}_{x} \mathrm{Ge}_{1-x}(0.93<x<0.96)$ single crystal significantly depended on the doping level. ${ }^{16}$ Kawazoe et al ${ }^{10}$ proposed the empirical composition relationship between P and Ge in CZ Si single crystal (i) to avoid the abnormal crystal growth and (ii) to prevent the lattice distortion resulted from high doping level of P. ${ }^{10}$ These studies suggest that $\mathrm{Ge}$ is a plausible co-doping candidate to grow the low-resistivity P-doped CZ Si crystal; however, their results were case dependent. There is no satisfactory understanding of the Ge impact on the $\mathrm{P}$ behavior in liquid and solid Si yet. Consequently, the phase equilibria at the Si-rich corner of the Ge-P-Si ternary system is of significant importance.
Here, we implemented calculation of phase diagrams (CALPHAD) and density functional theory (DFT) calculations at the Si-rich corner of the Si-Ge-P ternary system to reveal the influence of $\mathrm{Ge}$ co-doping on the heavily P-doped $\mathrm{Si}$. CALPHAD methods in this work serve the purpose of evaluating the solidification path of the $\mathrm{Si}(\mathrm{P}, \mathrm{Ge})$ ternary alloy and calculating the $K_{\text {eq }}$ of $\mathrm{P}$ in relevant $\mathrm{Si}(\mathrm{P}, \mathrm{Ge})$. DFT calculations attempt to discover the effect of $\mathrm{Ge}$ on preventing $\mathrm{P}$ diffusion in Si.

\section{A Brief Review of Previous Work on Phase Equilibria}

To date, neither phase equilibria nor thermodynamic properties of the Ge-P-Si ternary system is available. Nevertheless, phase diagrams of the involved three binary end-member systems, namely, Ge-Si, Ge-P and Si-P, have been experimentally and thermodynamically studied. ${ }^{2,3,17-26}$ The Ge-Si system has a continuous solid solution phase diagram. The first review and thermodynamic evaluation of its phase equilibria was reported by Olesinski et al. ${ }^{17}$ Then in 1992, Bergman et al. ${ }^{18}$ determined the partial enthalpy of $\mathrm{Si}$ in the Si-Ge liquid state at $1327 \mathrm{~K}$ in the concentration range of $0<x_{\mathrm{Si}}<0.03$. Based on the derived excess Gibbs energy of liquid over the entire composition range, they performed the thermodynamic investigation on the Si-Ge phase diagram that agreed well with the assessment work published in Ref. 17. The thermodynamic description of $\mathrm{Si}-\mathrm{Ge}$ is included in the work of Scientific Group Thermodata Europe (SGTE) where the modification has been built upon the combination of Refs. 17 and 18. In this work, the thermodynamic parameters for the Ge-Si system are directly taken from the SGTE Solution database version 4.9 (SSOL4). ${ }^{19}$

Among these three binary systems, the Si-P system has been subjected to the most extensive theoretical investigations. ${ }^{2,3,20-23}$ The first thermodynamic evaluation of this system was achieved by Olesinski et al. ${ }^{20}$ They proposed the equilibrium phase diagram of the Si-P binary system covering the entire composition range. In 2009, Tang et al. developed a thermodynamic database for fabricating solar cell grade silicon materials (SOG-Si). That database covered the reassessment of the Si-rich corner phase equilibria of the Si-P system. ${ }^{21}$ Arutyunyan et al. ${ }^{23}$ optimized the thermodynamic description of phases at the Si-rich side as well by using their in-house software. Jung and Zhang ${ }^{2}$ conducted the first complete thermodynamic assessment of the Si-P system. Later, Liang and Schmid-Fetzer ${ }^{3}$ thermodynamically reoptimized the description of the Si-P system through critically reviewing all available original experimental data. In addition to $\mathrm{SiP}$, they introduced a second intermediate compound $\mathrm{SiP}_{2}$ in the $\mathrm{Si}-\mathrm{P}$ phase diagram. The challenge of reproducing all the measured solidus and solvus of $\mathrm{Si}$ has 
been highlighted. Because of the largely scattered solubility of $\mathrm{P}$ in Si solid, they developed two alternative sets of selfconsistent thermodynamic parameters. ${ }^{3}$ There is no doubt that these independent sets of thermodynamic descriptions for Si-P can serve their individual targets. However, no clear definition is available for the lattice stability of metastable diamond structural P (P_diamond). It is critical for the description of the Gibbs free energy of the relevant diamond solution phases, such as $\mathrm{Si}(\mathrm{P})$ and $\mathrm{Ge}(\mathrm{P})$. In this work, DFT calculations were conducted to derive the lattice stability of metastable P_diamond. Accordingly, the modification of $\mathrm{Si}-\mathrm{P}$ is performed.

The Ge-P binary is not less complex than the Si-P system. Regarding the temperature-composition $(T-x)$ phase diagram of the Ge-P binary system, it was initially constructed based on differential thermal analysis (DTA) results of 12 bulk alloys (i.e. 10 at. $\%, 20$ at. $\%, 30$ at. $\%, 40$ at. $\%, 45$ at.\%, 50 at. $\%, 55$ at. $\%, 60$ at. $\%, 65$ at. $\%, 75$ at. $\%, 80$ at. $\%$ and 90 at.\% P). ${ }^{24}$ These alloys were prepared by melting at $960^{\circ} \mathrm{C}$ for 10-12 h under elevated argon pressure, and subsequently annealed at unspecified temperature for $300 \mathrm{~h}$. DTA were then carried out in a structured chamber into which inert gas (nitrogen and argon) was introduced under a certain pressure (unspecified in Ref. 24). The acquired heating curves were adopted to construct the $T-x$ diagram in the temperature range of $400-1000^{\circ} \mathrm{C}$. The $T-x$ diagram includes the liquidus boundaries and two invariant reactions, i.e. (i) peritectic reaction of liquid $+\mathrm{Ge} \rightarrow \mathrm{GeP}$ at $725^{\circ} \mathrm{C}$ (liquid composition $\sim 63$ at. $\% \mathrm{P}$ ), and (ii) an undefined invariant reaction involving liquid, $\mathrm{P}$ and GeP. Although the sample preparation process has been introduced in detail by Goncharov et al. ${ }^{24}$ they did not clarify whether the constructed $T-x$ phase diagram of Ge-P was referring to a constant pressure. In their later publication, ${ }^{25}$ in addition to the DTA results, they have reported the data measured via a static manometric method. Based on the measured data and thermodynamic analysis of the interaction of components, Ugai et al. ${ }^{25}$ constructed the pressure-temperature-composition $(P-T-x)$ diagram of the Ge-P binary system that was projected on the $T-x, P-T$ and $P-x$ planes. The solid solubility of $\mathrm{P}$ in $\mathrm{Ge} \_$diamond has been determined by means of microhardness measurements ${ }^{26}$ and Hall effect measurements. ${ }^{27}$ Abrikosov et al ${ }^{26}$ investigated the solubility of $\mathrm{P}$ in $\mathrm{Ge}$ _diamond at $500^{\circ} \mathrm{C}, 600^{\circ} \mathrm{C}, 700^{\circ} \mathrm{C}, 800^{\circ} \mathrm{C}, 850^{\circ} \mathrm{C}$ and $900^{\circ} \mathrm{C}$. Samples that have been made of single-crystal Ge (impurity level under $10^{-5} \%$ ) and P_red $(99.95 \% \mathrm{P})$, were annealed at a given temperature for 320-1000 $\mathrm{h}$ to achieve the equilibrium. By combining microstructural and chemical analyses with microhardness measurements, they proposed the solubility boundary of P in Ge_diamond. It was found that the maximum $\mathrm{P}$ solubility in Ge_diamond was 0.45 at. $\% \mathrm{P}$ at $600^{\circ} \mathrm{C}$. However, the equilibrium solid solubility of $\mathrm{P}$ in $\mathrm{Ge}$ at $670^{\circ} \mathrm{C}$ was 0.12 at.\% according to the supersaturated $\mathrm{Ge}(\mathrm{P})$ solid solution decomposition investigation. ${ }^{28}$ Hall effect measurements were conducted on the $\mathrm{P}$-doped CZ Ge single-crystal to study the solubility of $\mathrm{P}$ in $\mathrm{Ge}$ _diamond in the temperature range of $300-880^{\circ} \mathrm{C} .^{27}$ Before characterizing the Hall carrier concentration, Fistul et al. have pretreated samples by annealing at $800^{\circ} \mathrm{C}$ for $2 \mathrm{~h}$ and quenching in ethylene glycol (with the cooling rate of $200^{\circ} \mathrm{C} / \mathrm{s}$ ). Besides, the measurement error has been controlled to be under $5 \%$ by adopting proper shape of sample and high magnetic fields $(16 \mathrm{kA} / \mathrm{m})$. Based on the collected kinetic annealing curves, Fistul et al. have found that $\mathrm{P}$ in Ge_diamond exhibited retrograde solubility. The maximum concentration of $\mathrm{P}$ in Ge_diamond was $7 \times 10^{19}$ atom $/ \mathrm{cm}^{3}$ (or, $\sim 0.16$ at.\% P) at $800^{\circ} \mathrm{C},{ }^{27}$ rather than the previously reported 0.45 at. $\%$ at $600{ }^{\circ} \mathrm{C} .{ }^{26}$ Nevertheless, the P solubility in $\mathrm{Ge}$ at $650^{\circ} \mathrm{C}$ was $\sim 4.7 \times 10^{19}$ atom $/ \mathrm{cm}^{3}$ (or, $\sim 0.11$ at. $\%$ $\mathrm{P})$, which is in good agreement with the experimental data (0.12 at.\%) in Ref. 27.

Thermodynamic properties of GeP have been relatively well studied. ${ }^{29-39}$ Ugai et al. ${ }^{31}$ measured the low temperature heat capacity of $\mathrm{GeP}$ by means of a calorimeter in temperature range of $6.99-304.83 \mathrm{~K}$. The high temperature heat capacity of $\mathrm{GeP}$ has never been experimentally measured. The $C_{p}$ expression of $\mathrm{GeP}$ above room temperature was estimated in literature. ${ }^{32-34}$ For instance, in the first compilation of thermodynamic properties of inorganic compounds, Barin et al. ${ }^{32}$ estimated the heat capacity of $\mathrm{GeP}(298-1700 \mathrm{~K})$ to be $C_{p}=43.3+0.0113 \cdot T-5.23 \cdot 10^{5} \cdot T^{-2} \mathrm{~J} \mathrm{~mol}^{-1} \mathrm{~K}^{-1}$. In other versions of the compilations, it has been modified to be $C_{p}=45.4+0.0113 \cdot T-5.2 \cdot 10^{5} \cdot T^{-2} \mathrm{~J} \mathrm{~mol}^{-1} \mathrm{~K}^{-1}$. 33,34 However, these compilations provide the identical enthalpy of formation and entropy of GeP at $298.15 \mathrm{~K}$ (i.e. $\Delta H_{298}^{0}$ and $\left.S_{298}^{0}\right) .{ }^{32-34}$ Zumbusch et al. ${ }^{29}$ and Süss et al. ${ }^{30}$ have determined the dissociation pressure of $\mathrm{GeP}$ in the temperature ranges of 773-832 K and 773-973 K, respectively. However, we noticed an error for the unit of the $y$-axis in the decomposition pressure graph, i.e. Fig. 3 in Ref. 30. It is in $\mathrm{Pa}$ rather than in $\mathrm{kPa}$. One reason is that the experimental data from [2930] was in the level of $10^{4} \mathrm{~Pa}$. Those data were superimposed in Fig. 3 of Ref. 30; however, they were presented in the range of $10^{4}-10^{5} \mathrm{kPa}$ rather than $10-10^{2} \mathrm{kPa}$. The error was also evidenced by proposed expression of the total dissociation pressure of $\mathrm{GeP}$ as a function of temperature. ${ }^{30} \mathrm{Zumbusch}$ et al. ${ }^{29}$ and Süss et al. ${ }^{30}$ also calculated $\Delta H_{298}^{0}$ and $S_{298}^{0}$ of GeP according to the reactions: $4 \mathrm{GeP}=4 \mathrm{Ge}(\mathrm{s})+\mathrm{P}_{4}(\mathrm{~g})$ at $540^{\circ} \mathrm{C}$ and $\mathrm{Ge}(\mathrm{s})+\mathrm{P}(\mathrm{s}$, white $)=\mathrm{GeP}(\mathrm{s})$ and, $\mathrm{Ge}(\mathrm{s})+1 / 4 \mathrm{P}_{4}(\mathrm{~g})=\mathrm{GeP}(\mathrm{s})$ and $\mathrm{P}_{4}(\mathrm{~g})=2 \mathrm{P}_{2}(\mathrm{~g})$, respectively.

Olesinski et al. ${ }^{40}$ summarized and reviewed the phase equilibria $^{24-28}$ and thermodynamic properties ${ }^{29-32}$ of the Ge-P system that were published before 1985. They assessed the steady-state temperature-composition $(T-X)$ phase diagram of Ge-P at $4600 \mathrm{kPa}^{40}$ with respect to the reported data 
in literature. ${ }^{25,29,30,32}$ For instance, the liquidus boundary of Ge-P phase diagram at $4600 \mathrm{kPa}$ has been determined based on the determined liquidus data from. ${ }^{25}$ However, Olesinski et al. ${ }^{40}$ has stated that the evaluated phase diagram was valid only on the condition of that the pressure should guarantee the melting of $\mathrm{P}$ rather than sublimation in the given temperature ranges. For instance, the pressure should be no less than $4300 \mathrm{kPa}$, as proposed in Ref. 24. In addition, the solid solubility of P in Ge_diamond was ignored in Ref. 40. In view of this, the re-assessment of the Ge-P phase diagram is essential to reproduce the $\mathrm{Ge}(\mathrm{P})$ solidus.

\section{Calculation Methods}

\section{CALPHAD}

In the present work, the phase equilibria of the Ge-P-Si ternary system are thermodynamically extrapolated by combining the Ge-Si database from SGTE, ${ }^{19}$ the currently optimized Ge-P and Si-P descriptions. The lattice stability of the element $i(i=\mathrm{Ge}, \mathrm{P}$ and $\mathrm{Si})$ is attributed to the enthalpy of its stable state at $298.15 \mathrm{~K}$ and $100 \mathrm{kPa}, H_{i}^{\mathrm{SER}}$, as recommended by SGTE. ${ }^{41}$ The Ge-P-Si ternary system includes three solution phases (i.e. liquid, Si_diamond and Ge_diamond), as well as three intermetallic compounds (namely, GeP, SiP and $\mathrm{SiP}_{2}$ ). An ordinary substitutional solution model is applied to describe these solution phases. Thermodynamic parameters were evaluated using the PARROT optimization module in the $2018 \mathrm{~b}$ version of the Thermo-Calc software package. ${ }^{42}$

The molar Gibbs energy of a solution phase $\phi$ can be represented as a sum of the Gibbs energy for the involved components $i$, the ideal entropy term describing a random mixing of components, and the excess Gibbs energy describing the deviation from the ideal behavior, i.e.,

$G^{\phi}=\sum_{i} x_{i}^{o} G_{i}^{\phi}+R T \sum_{i} x_{i} \ln \left(x_{i}\right)+{ }^{\mathrm{ex}} G^{\phi}$

where $R$ is the gas constant, $T$ is the absolute temperature, $x_{i}$ is the molar fraction of component $i(i=\mathrm{Ge}, \mathrm{P}, \mathrm{Si}),{ }^{o} G^{\phi}$ denotes the molar Gibbs energy of $i$, with reference state of $\phi$. The term ${ }^{\text {ex }} G^{\phi}$ describes the excess Gibbs energy that has not been represented by the first two terms. For the involved binary systems (i.e. Ge-P, Ge-Si, and P-Si), the molar excess Gibbs energies, ${ }^{\text {Bin.ex }} G^{\phi}$, were expressed as:

${ }^{\text {Bin.ex }} G^{\phi}=\sum_{i} \sum_{j>i} x_{i} x_{j} \alpha_{i j}$

For solution phases in binary systems, the Redlich-Kister (RK) power series has been adopted to describe the composition dependence for the binary interaction parameters $L_{i j}^{v}$ : $\alpha_{i, j}=\sum_{v}\left(x_{i}-x_{j}\right)^{v} L_{i, j}^{v}$

The values of $L_{\mathrm{Ge}, \mathrm{Si}}^{v}$ were directly cited from, ${ }^{19} L_{\mathrm{Si}, \mathrm{P}}^{v}$ and $L_{\mathrm{Ge}, \mathrm{P}}^{v}$ of both liquid and diamond solution phases have been optimized in this work. For the Ge-P-Si ternary system, no ternary interaction parameters $\left(L_{i, j, k}\right)$ are evaluated in the present work since no experimental data are available. The ternary molar Gibbs energy ${ }^{\text {Tern.ex }} G^{\phi}$ is extrapolated from contributions of the three binary subsystems. To add these contributions together, several methods have been developed by applying certain geometric principles, for instance, Muggianu method, Kohler method and Toop method. ${ }^{43-46}$ In this work, $\mathrm{Ge}$ and $\mathrm{Si}$ are chemically similar, however, $\mathrm{P}$ has very different chemical behavior concerning chemical behaviors of components $\mathrm{Ge}$ and $\mathrm{Si}$. Therefore, an asymmetric method (i.e. Kohler-Toop module) has been adopted as recommended by Refs. 43-46. Here, P is defined as the Toop constituent. Ge and $\mathrm{Si}$ are specified as the Kohler constituents. Accordingly, the excess Gibbs energy of ternary solution phase is written as:

$$
\begin{aligned}
{ }^{e x} G^{\phi}= & x_{\mathrm{Ge}} x_{\mathrm{P}}\left[\left(x_{\mathrm{Ge}}-x_{\mathrm{P}}-x_{\mathrm{Si}}\right)^{v} L_{\mathrm{Ge}, \mathrm{P}}^{v}\right]+x_{\mathrm{P}} x_{\mathrm{Si}}\left[\left(x_{\mathrm{P}}-x_{\mathrm{Si}}-x_{\mathrm{Ge}}\right)^{v} L_{\mathrm{P}, \mathrm{Si}}^{v}\right] \\
& +x_{\mathrm{Ge}} x_{\mathrm{Si}}\left[\left(x_{\mathrm{Ge}}-x_{\mathrm{Si}}+\frac{\left(x_{\mathrm{Ge}}-x_{\mathrm{Si}}\right)}{\left(x_{\mathrm{Ge}}+x_{\mathrm{Si}}\right)} \cdot x_{1}\right)^{v} L_{\mathrm{Ge}, \mathrm{Si}}^{v}\right]
\end{aligned}
$$

Regarding the three intermetallic compounds, descriptions of $\mathrm{SiP}$ and $\mathrm{SiP}_{2}$ are directly cited from, ${ }^{3}$ and that of $\mathrm{GeP}$ is thermodynamically assessed in this work, as described by following:

$G_{\mathrm{GeP}}^{0}=\left(\Delta H_{298}^{0}+\int_{T=298}^{T} C_{p} \mathrm{~d} T\right)-T\left(S_{298}^{0}+\int_{T=298}^{T}\left(\frac{C_{p}}{T}\right) \mathrm{d} T\right)$

Evaluated expression of $C_{p}$ above room temperature in Refs. 32-34 generate slightly smaller values (40.79 J/ mol K${ }^{32}$ and $42.89 \mathrm{~J} / \mathrm{mol} \mathrm{K}^{33,34}$ ) than the experimentally determined $C_{p}$ of GeP at $298.15 \mathrm{~K}(44.35 \mathrm{~J} / \mathrm{mol} \mathrm{K})$ by Ref. 31. In this work, the evaluated expression from ${ }^{33,34}$ has been directly adopted, as the discrepancy between evaluated values and measured data was acceptable. Formation enthalpy of $\mathrm{GeP}$ at $0 \mathrm{~K}$ and normal atmosphere has been widely studied via DFT calculations in several open database platforms, such as Open Quantum Materials Database (OQMD), ${ }^{37}$ Material Project ${ }^{38}$ and Aflow, ${ }^{39}$ as summarized in Table I. However, various lattice parameters and band gaps have been adopted to calculate the total energy of GeP by those platforms. This, together with the various pseudopentials of ground state of Ge and P, can partially interpret the large discrepancy among the theoretically calculated formation enthalpy $(\Delta H)$. As such, the comparison of these calculated data was impossible. On the other hand, the DFT calculated 


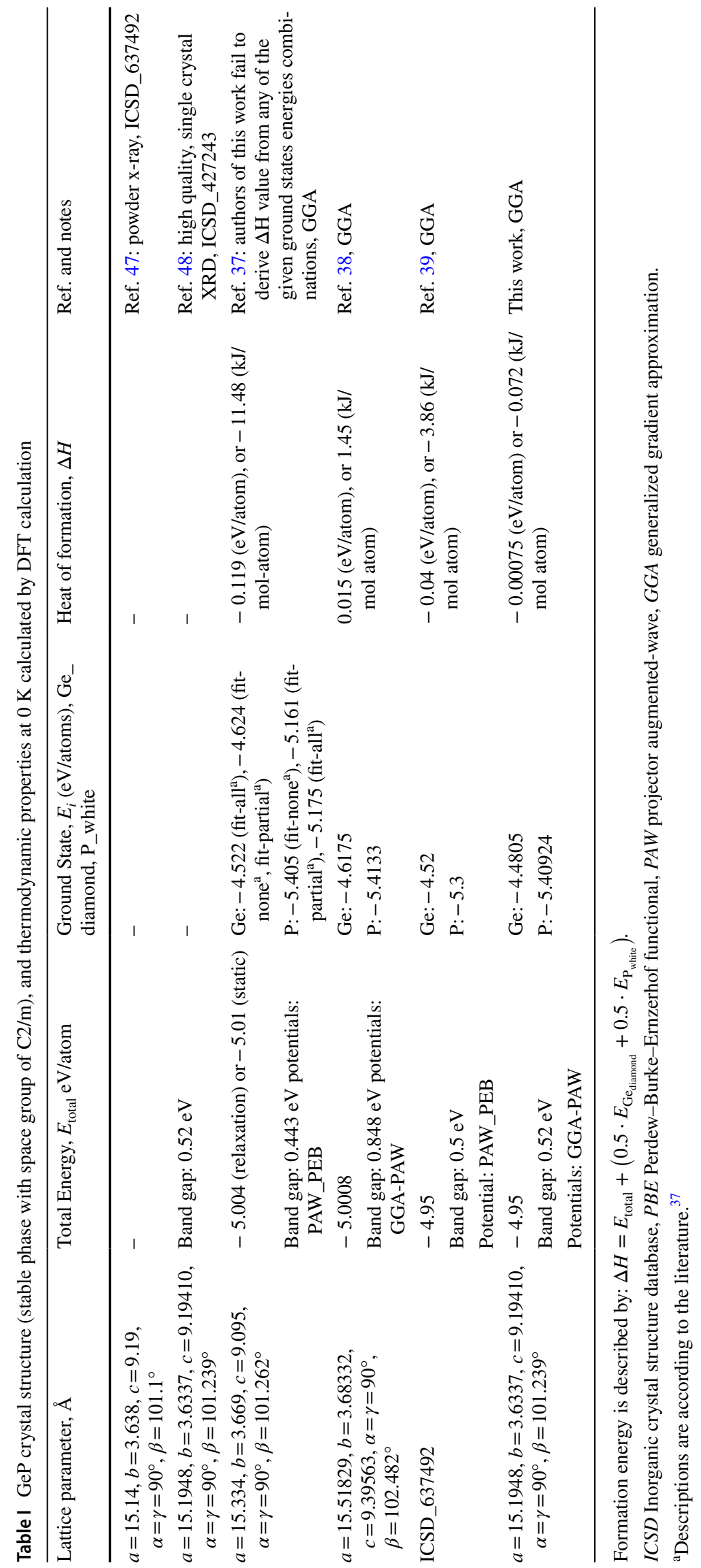


Table II Thermodynamic properties of Ge1P1 at $298 \mathrm{~K}$, including data published in literature, and calculated in this work based on assessed thermodynamic parameters

\begin{tabular}{lll}
\hline $\begin{array}{l}\text { Enthalpy of formation } \\
\Delta H_{298}^{0}(\mathrm{~kJ} / \mathrm{mol} \text { atom })^{\mathrm{a}}\end{array}$ & $\begin{array}{l}\text { Entropy } S_{298}^{0}(\mathrm{~kJ} / \\
\text { mol atom })\end{array}$ & Ref. \\
\hline-12.56 & - & Experimental $^{29}$ \\
-10.5 & 31.5 & Reviewed $^{35}$ \\
$-12.19 \pm 1.5$ & $27.64 \pm 3.32$ & Experimental $^{30}$ \\
- & 26.42 & Experimental $^{31}$ \\
-13.6 & 30.54 & $32-34$ \\
-13.82 & 25.57 & CALPHAD, this work \\
\hline
\end{tabular}

${ }^{a}$ Enthalpy of formation of Ge1P1 refers to Ge_diamond and P_white structures.

total formation energies can serve as a starting point when no experimental data are available. For GeP, the experimentally measured standard formation enthalpy of GeP in Refs. 29-31 are in good agreement, as listed in Table II. Accordingly, the measured $\Delta H_{298}^{0}$ and $S_{298}^{0}$ at $298.15 \mathrm{~K}$ in Refs. 29 and 31 have been utilized to derive the Gibbs energy of GeP. In order to reproduce the dissociation of GeP, the formation enthalpy of GeP at $298.15 \mathrm{~K}$ has been slightly modified.

\section{Density Functional Theory Calculation}

Density functional theory calculations have been applied to find the formation energy of the GeP compound, monovacancy formation energy of $\mathrm{Si}$, substitutional solute energies of dopants ( $\mathrm{P}$ and $\mathrm{Ge}$ ) in $\mathrm{Si}$, and the 1st, 2nd, and 3rd neighbored di-doping formation energies. The calculation was performed by using the projector augmented wave (PAW) method, ${ }^{49,50}$ as implemented in the highly efficient Vienna ab initio simulation package (VASP). ${ }^{51,52}$ GGA was used for the exchange-correction functional. In this work, total energy of GeP (with a space group of $\mathrm{Cs} / \mathrm{m}$ ) has been calculated by using crystal constants from Ref. 48 It is reported as high quality in ICSD. Regarding energies related to Si_diamond structure, two sets of cubic supercells, 64 atoms $(2 \times 2 \times 2)$ and 216 atoms $(3 \times 3 \times 3)$, have been utilized in relevant simulations. The total energies of each supercell have been converged to less than $0.1 \mathrm{meV}$ with respect to electronic, ionic and unit cell degrees of freedom by using the constant planewave energy cutoff of $600 \mathrm{eV}$. The $7 \times 7 \times 7$ and $3 \times 3 \times 3 \mathrm{k}$-point meshes were chosen to integrate the supercell structure of 64 and 216 atoms over the Brillouin zone, respectively. These k-points were determined to be sufficiently large to perform the relevant calculations.

In order to gain insight into the Ge impact on the diffusional difficulty of $\mathrm{P}$ in a Si matrix, the climbing image nudged elastic band method (CI-NEB) $)^{53,54}$ has been employed to find the so-called minimum-energy pathways (MEPs) for $\mathrm{P}$ migration as a sequence of intermediate configurations. The supercell with 64 atoms was used for the 1NN P atomic jumping geometry calculations. The ground state energies were determined by GGA level of theory. Five intermediate images between nearest local-energy minimum configurations were used in NEB calculation to find the energy barrier for the nearest neighbor $\mathrm{P}$ diffusion with/ without co-existing Ge.

\section{Results and Discussion}

\section{Thermodynamic Evaluation of the Ge-P-Si System}

In this work, the thermodynamic optimizations were conducted on the Ge-P system and the Si-rich side of the Si-P system. The experimental data of phase equilibria in Ge-P from Refs. 24 and 25 were measured under different pressures. Thus, the current optimization of the Ge-P phase diagram was started by reproducing the more reliable decomposition pressure of GeP. ${ }^{29,30}$ Subsequently, the parameters of the liquid phase were optimized based on the experimentally measured invariant reactions, i.e. three-phase equilibrium of liquid-Ge-gas and liquid-GeP-gas. ${ }^{31}$ The solubility of $\mathrm{P}$ in solid Ge was the last term brought into the optimization.

Figure 1 illustrates the decomposition pressure of GeP obtained in this work, along with the experimental data from Refs. 29 and 30. The calculated decomposition temperatures under various pressure conditions fit well with the experimentally determined values. The measured three-phase equilibria (i.e. liquid-Ge-gas, and liquid-GeP-gas) were depicted on the pressure-temperature and pressure-composition projections. As shown in Fig. 2, a satisfactory agreement has been obtained between those experimental results and calculated data of this work.

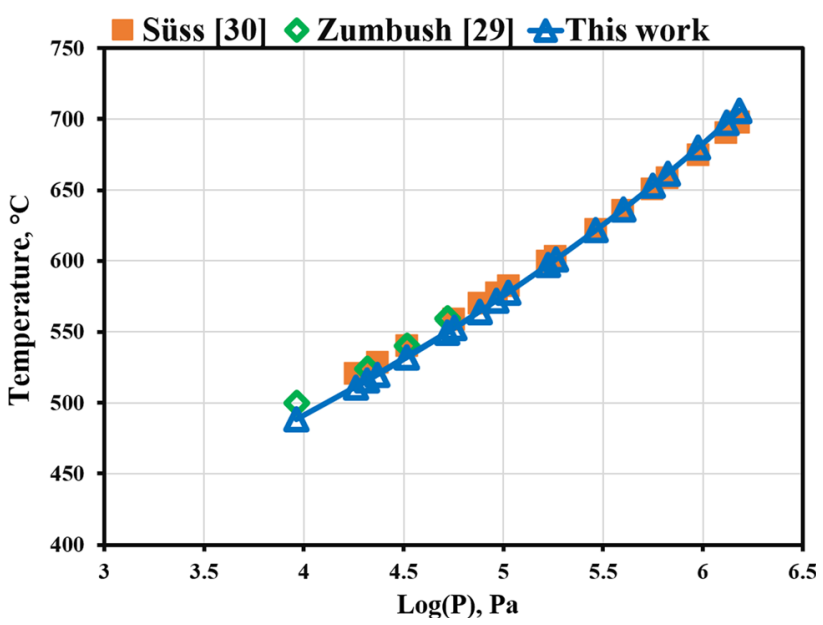

Fig. 1 Decomposition pressure of $\mathrm{GeP}: \mathrm{GeP}(\mathrm{s})=\mathrm{Ge}(\mathrm{s})+\mathrm{P}$ (gas). $\mathrm{X}$-axis is the total phosphorus pressure, with majority gas species of $\mathrm{P}_{2}$ and $\mathrm{P}_{4}$. 


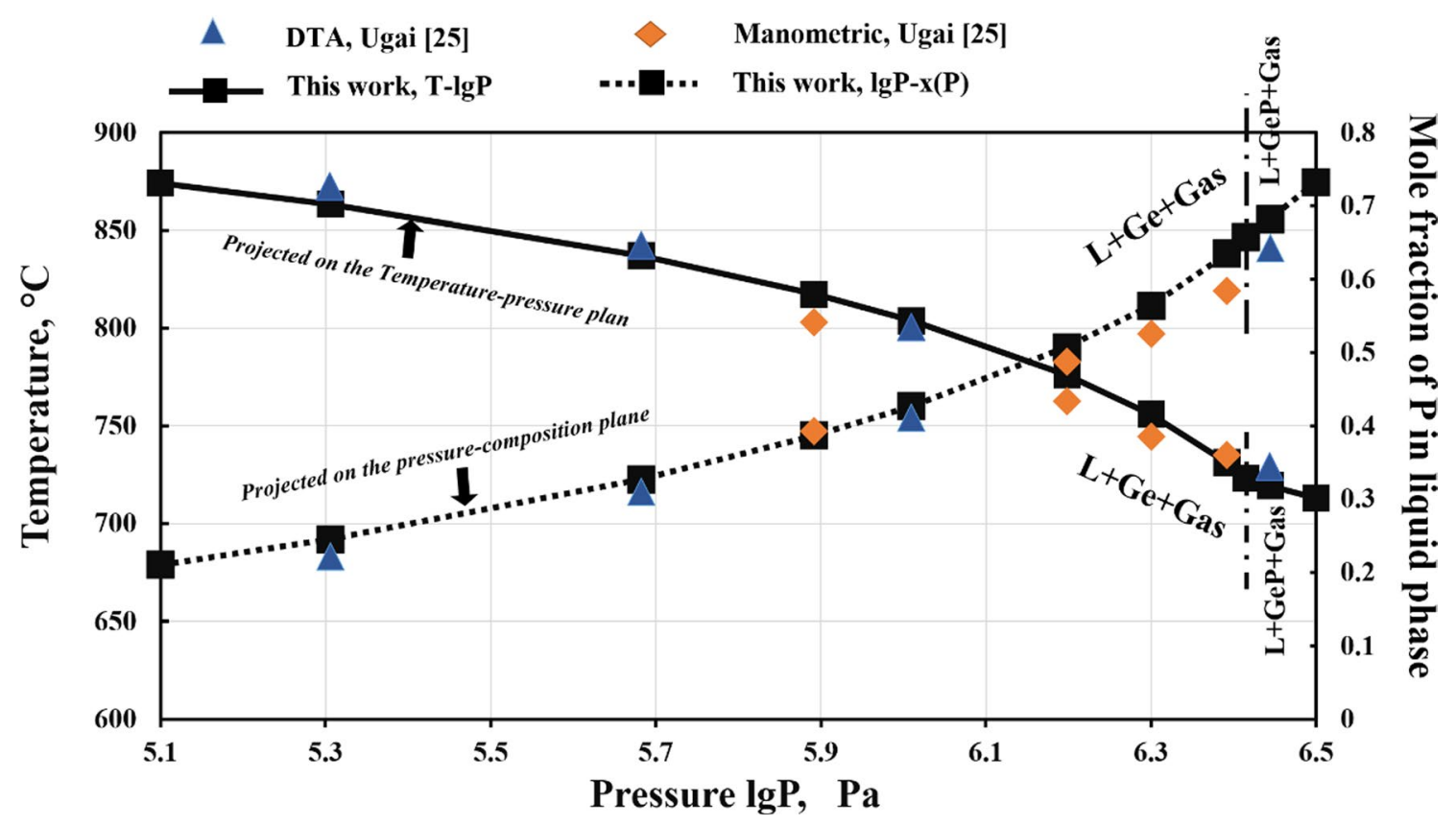

Fig. 2 Three-phase equilibrium, i.e. liquid-Ge-gas and liquid-GePgas, projected on the temperature-pressure and pressure-composition planes. In the graph, $\mathrm{L}$ denotes the liquid phase. The vertical dash-

Figure $3 \mathrm{a}$ and $\mathrm{b}$ show the calculated phase diagrams of Ge-P along with the published data of phase equilibria. ${ }^{24-28,40}$ Less weight was given for data determined by microhardness in Ref. 26 that are much higher than all the others. ${ }^{27,28}$ The phase diagram at $4600 \mathrm{kPa}$ (Fig. 3a) has been calculated in which the liquidus evaluated by Olesinski et al. ${ }^{40}$ was superimposed. Results from Ref. 24 were also plotted on Fig. 3a for providing available experimental points in the literature, as that has been done in Ref. 40. Comparing the evaluated liquidus by Olesinski et al., ${ }^{40}$ the liquidus calculated in this work is slightly closer to the P edge. Nevertheless, such deviation should be ascribed to the different lattice stabilities of elements adopted in this work ${ }^{41}$ and that reported in Ref. 40. This is evidenced by the different melting temperature of $\mathrm{P} \_$red at $4600 \mathrm{kPa}$. For instance, $\mathrm{P} \_$red had a melting point of $593^{\circ} \mathrm{C}$ in Ref. 40 , while it is $578.9^{\circ} \mathrm{C}$ according to SGTE ${ }^{41}$ adopted in this work. Figure $3 \mathrm{~b}$ shows the Ge-rich side of the Ge-P binary phase diagram under normal atmosphere. The calculated single-phase boundary (SPB) of the solid solution phase, i.e. Ge_diamond (hereinafter, denoted as $\mathrm{Ge}(\mathrm{P})$ ), agreed well with the measured solid solubilities of $\mathrm{P}$ in Ge_diamond. ${ }^{27,28}$ It is evident that a set of self-consistent thermodynamic parameters of Ge-P was achieved here. Therefore, the phase diagram of Ge-P at normal atmosphere has been extrapolated based on the Ge-P thermodynamic description acquired in this work, as shown in Fig. 3c. dotted lines represent the delimitation of these three-phase equilibrium region based on pressure variations.

Regarding the solid solubility of P in Si_diamond (hereinafter denoted as $\mathrm{Si}(\mathrm{P})$ ), there are extensive thermodynamic calculations and experimental measurements. , $, 3,21-23,55-60^{-}$ The determined P solubility boundaries in Si solid scattered largely. The experimental phase equilibria have been critically reviewed by Jung et al. ${ }^{2}$ and Liang et al. ${ }^{3}$ Hereby, no space is taken for repeating the review in this paper.

As described in "A Brief Review of Previous Work on Phase Equilibria" section, the Si-rich side of the Si-P system requires a re-optimization owing to the reliable lattice stability of metastable P_diamond. In this work, the thermodynamic parameters of $\mathrm{Si}(\mathrm{P})$ and liquid solution have been re-optimized with reference to the work of Liang and Schmid-Fetzer ${ }^{3}$ owing to their insight evaluation into the original experimental works. Here, the author also initially attempted to divide the measured $\mathrm{P}$ solubility limits in $\mathrm{Si}_{-}$ diamond into two groups as the strategy applied by Liang and Schemid-Fetzer. ${ }^{3}$ Accordingly, two sets of parameters (Model I and II) were achieved to reproduce the scattered single-phase boundary of the $\mathrm{Si}(\mathrm{P})$ solution phase. As illustrated in Fig. 4, these calculated P solubility boundaries are in satisfactory agreement with each group of the reported data, except for data from Ref. 26. The P solubility in Si_diamond determined by microhardness measurements ${ }^{26}$ represented the lowest solubility boundary among those reported data. During this optimization, a small weight has been given to data from Ref. 26 since the technique was considered inadequately sensitive. ${ }^{61}$ 

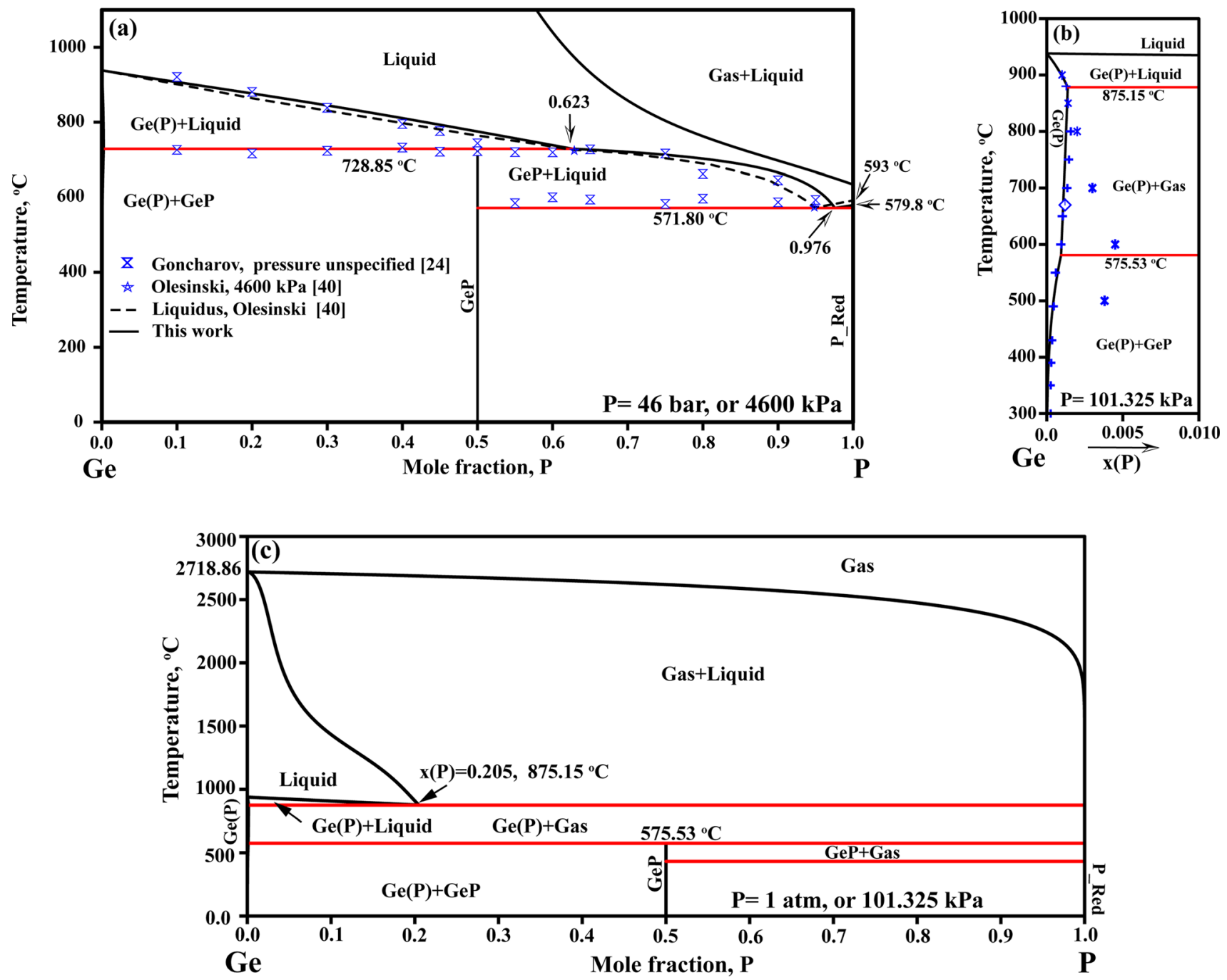

Fig. 3 (a) Phase diagram of Ge-P at $4600 \mathrm{kPa}$ superimposed with experimental data from Ref. 24 and evaluated data from Ref. 40, (b) Ge-rich side of Ge-P phase diagram at normal atmosphere $(p=101.325 \mathrm{kPa})$ with comparison between calculated SPB of Ge diamond and experimentally determined $\mathrm{P}$ solubility in $\mathrm{Ge}$ _diamond

On the other hand, the experimental data, representing the highest solubility limits, ${ }^{56,57,60}$ was rooted from the Si-P-O ternary system rather than the pure Si-P binary system. The oxygen originated either from the starting material ${ }^{56,57}$ or the subsequent annealing process. ${ }^{60}$ For instance, the slightly oxidizing atmosphere $\left(90 \% \mathrm{~N}_{2}+10 \% \mathrm{O}_{2}\right)$ was applied during the high-temperature heat treatment processes in Ref. 60. The Hall measurement is less accurate for hightemperature species since the concentration of electrically inactive phosphorus increases with temperature due to the phosphorus diffusion in silicon. This phenomenon becomes significant when the temperature is above $750^{\circ} \mathrm{C} .{ }^{60}$ Consequently, we adopted a third model to reproduce the $\mathrm{P}$ solubility boundary in $\mathrm{Si}$ solid, i.e. the solvus determined by Hall measurement (at relatively low temperature) $)^{58,59}$ and the (i.e., blue asterisk, ${ }^{26}$ blue plus, ${ }^{27}$ blue diamond ${ }^{28}$ ) and (c) full phase diagram of Ge-P at normal atmosphere $(p=101.325 \mathrm{kPa})$. Here, $\mathrm{Ge}(\mathrm{P})$ represents the solid solution phase of Ge_diamond in Ge-P binary system (Color figure online).

solidus determined by DTA. ${ }^{22}$ The calculated boundary was superimposed in the inserted graph of Fig. 4. The published experimental data were relatively well reproduced. Model III thus represented the most reliable set of description in this work. It has been utilized in the thermodynamic extrapolation of the Ge-P-Si equilibrium phase diagram.

In the $\mathrm{CZ} \mathrm{Si}$ growth process, the typical gas pressure is in the range of $1.5-5 \mathrm{kPa} .{ }^{1}$ The decomposition temperatures of $1: 1$ ratio phosphide in both $\mathrm{Ge}-\mathrm{P}$ and $\mathrm{Si}-\mathrm{P}$ systems decrease with lowering total pressure. It is, therefore, of great importance to extrapolate the phase diagrams of Ge-P and $\mathrm{Si}-\mathrm{P}$ to relevant process pressure, for instance $5 \mathrm{kPa}$.

Figure 5 shows the calculated phase diagrams of Ge-P and $\mathrm{Si}-\mathrm{P}$ at 1.5 and $5 \mathrm{kPa}$. The diamond solid and gas two-phase equilibrium region presented in both systems. The three-phase 


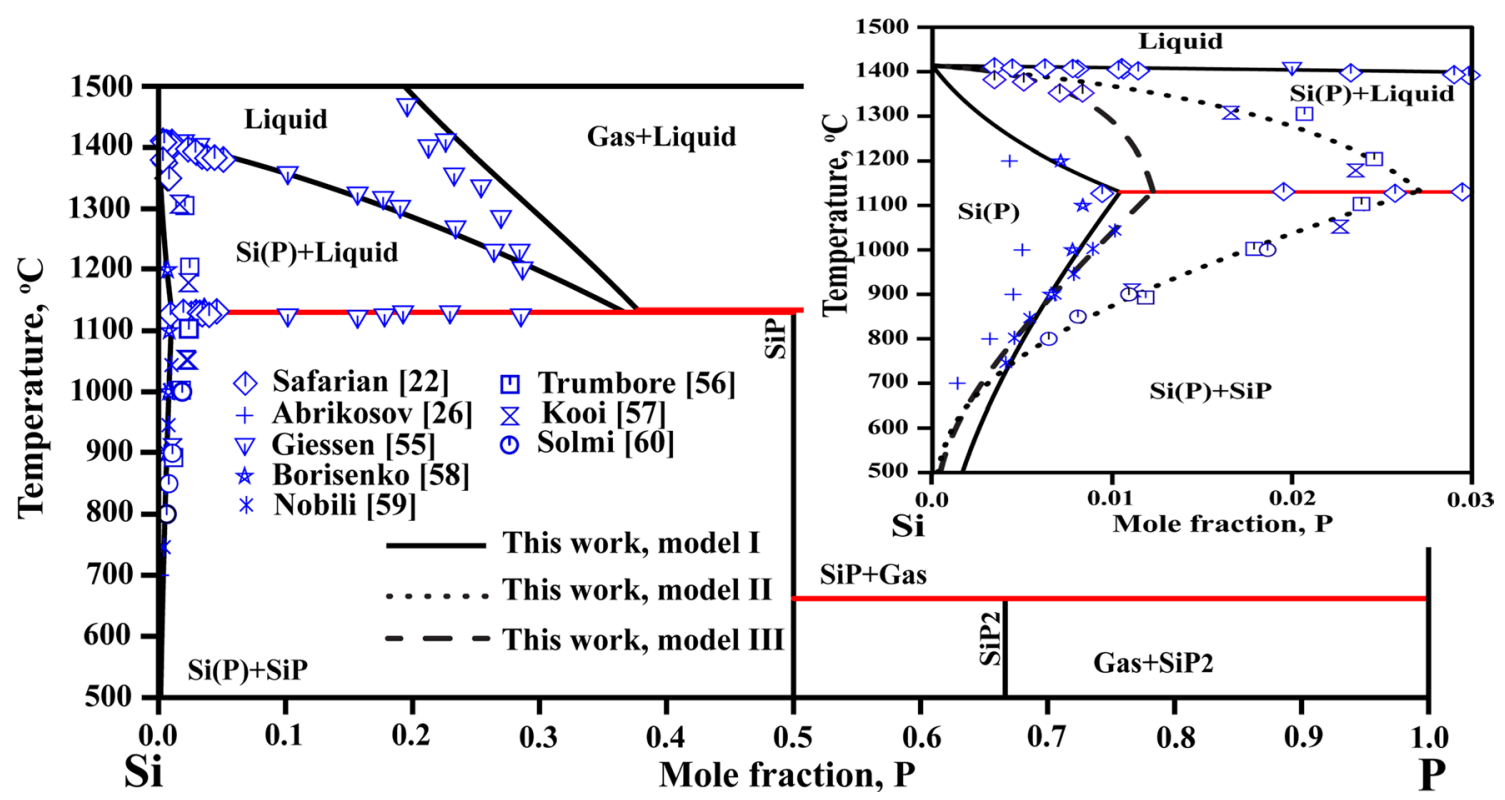

Fig. 4 Calculated Si-P phase diagram at $100 \mathrm{kPa}$, along with experimental phase equilibria data and the enlarged section at Si-rich side.

equilibria of phosphide-liquid-diamond were replaced by phosphide-gas-diamond in both systems as pressure lowered to $5 \mathrm{kPa}$. The temperature window for liquid-diamond two-phase co-existing regions shrank under such low-pressure condition, so did the solid solubility limit of $\mathrm{P}$ in both $\mathrm{Si}(\mathrm{P})$ and $\mathrm{Ge}(\mathrm{P})$ solids. These phenomena get more pronounced with further decreasing pressure, as shown in the relevant phase diagrams at $1.5 \mathrm{kPa}$ in Fig. $5 \mathrm{~b}$ and $\mathrm{d}$. These issues complicate the control of the growth process of heavily P-doped CZ Si single crystal. For instance, the evaporation of $\mathrm{P}$ starts at lower temperature when a lower pressure condition is applied.

For the Ge-P-Si ternary system, it was thermodynamically extrapolated based on the thermodynamic descriptions of the binary end-member systems, i.e. Ge-P was according to SGTE, ${ }^{19} \mathrm{Ge}-\mathrm{P}$ and Si-P were according to the current results. As no experimental investigation available, analytical methods were not attempted to assess the ternary interaction parameters. The geometric model has been utilized to extrapolate the thermodynamic description of the ternary solutions (i.e. $\mathrm{Si}(\mathrm{Ge}, \mathrm{P})$ and liquid phases). In this work, the Kohler-Toop model was the optimal model, in order to treat the very different chemical behavior of $\mathrm{P}$ from those of $\mathrm{Ge}$ and Si. The obtained thermodynamic parameters of this work are listed in Table III.

\section{Impacts of Ge}

\section{Impacts on Heavily P-doped Si during Growth}

The solidus lines of $\mathrm{Si}$ in Fig. 5c and $\mathrm{d}$ indicate that the maximum equilibrium $\mathrm{P}$ solubility in $\mathrm{Si}$ is around
$0.478-0.68$ at. \% under the typical gas pressure range $(1.5-5 \mathrm{kPa})$ of the CZ Si growth process. These mole fraction values correspond to a $\mathrm{P}$ atom density of around $2.39 \times 10^{20}-4.85 \times 10^{20}$ atoms $/ \mathrm{cm}^{3}$. The conversion between mole fraction $\left(x_{\mathrm{p}}\right)$ and atom density $\left(X_{p}\right)$ is as follows:

$X_{p}=\frac{\left(x_{\mathrm{P}} \cdot N_{\mathrm{A}} \cdot \rho_{\mathrm{Si}}\right)}{M_{\mathrm{Si}_{1-x} \mathrm{P}_{x}}}$

where $\mathrm{N}_{\mathrm{A}}$ is the Avogadro constant, $M_{\mathrm{Si}_{1-x} \mathrm{P}_{x}}$ is the atomic mass of the $\mathrm{Si}$ solution in $\mathrm{g} / \mathrm{mol}$ that is derived from atomic mass of $\mathrm{P}$ and $\mathrm{Si}$ in this work, i.e. $M_{\mathrm{Si}_{1-x} \mathrm{P}_{x}}=(1-x) M_{\mathrm{Si}}+x M_{\mathrm{P}}$. The density of $\mathrm{Si}, \rho_{\mathrm{Si}}$, in $\mathrm{g} / \mathrm{cm}^{3}$ is adopted for the conversion, for the following reasons: (i) negligible effect of $\mathrm{P}$ dopant level (i.e. $\leq 10^{18}$ atoms $/ \mathrm{cm}^{3}$ ) on the $\mathrm{Si}$ density ${ }^{12}$ and (ii) no experimentally measured density of $\mathrm{Si}$ at high $\mathrm{P}$ doping level.

Despite the small solid solubility of $\mathrm{P}$ in $\mathrm{Si}$, the P-doped CZ Si crystal with resistivity under $1 \mathrm{~m} \Omega \mathrm{cm}$ has been achieved. For instance, $\mathrm{Chiou}^{9}$ incorporated about $1.11 \times 10^{20}$ atom $/ \mathrm{cm}^{3} \mathrm{P}$ in CZ Si crystal and obtained a resistivity value of $0.71 \mathrm{~m} \Omega \mathrm{cm}$. The equilibrium $\mathrm{P}$ concentration in $\mathrm{Si}$ solid presented in Fig. $5 \mathrm{c}$ and d suggests the potential to further lower the resistivity by incorporating higher $\mathrm{P}$ level in $\mathrm{Si}$ crystal. For example, to achieve a resistivity value of $0.5 \mathrm{~m} \Omega \mathrm{cm}$, it requires dissolving around $1.65 \times 10^{20}$ atom/ $\mathrm{cm}^{3}$ (or 0.33 at.\%) $\mathrm{P}$ in $\mathrm{Si}$, according to the free-access resistivity-composition converter. ${ }^{62}$ This $\mathrm{P}$ doping level creates a lattice contraction of around $2.97 \times 10^{-4}$, as the lattice strain of substitutional solution is ${ }^{9,12}$ 

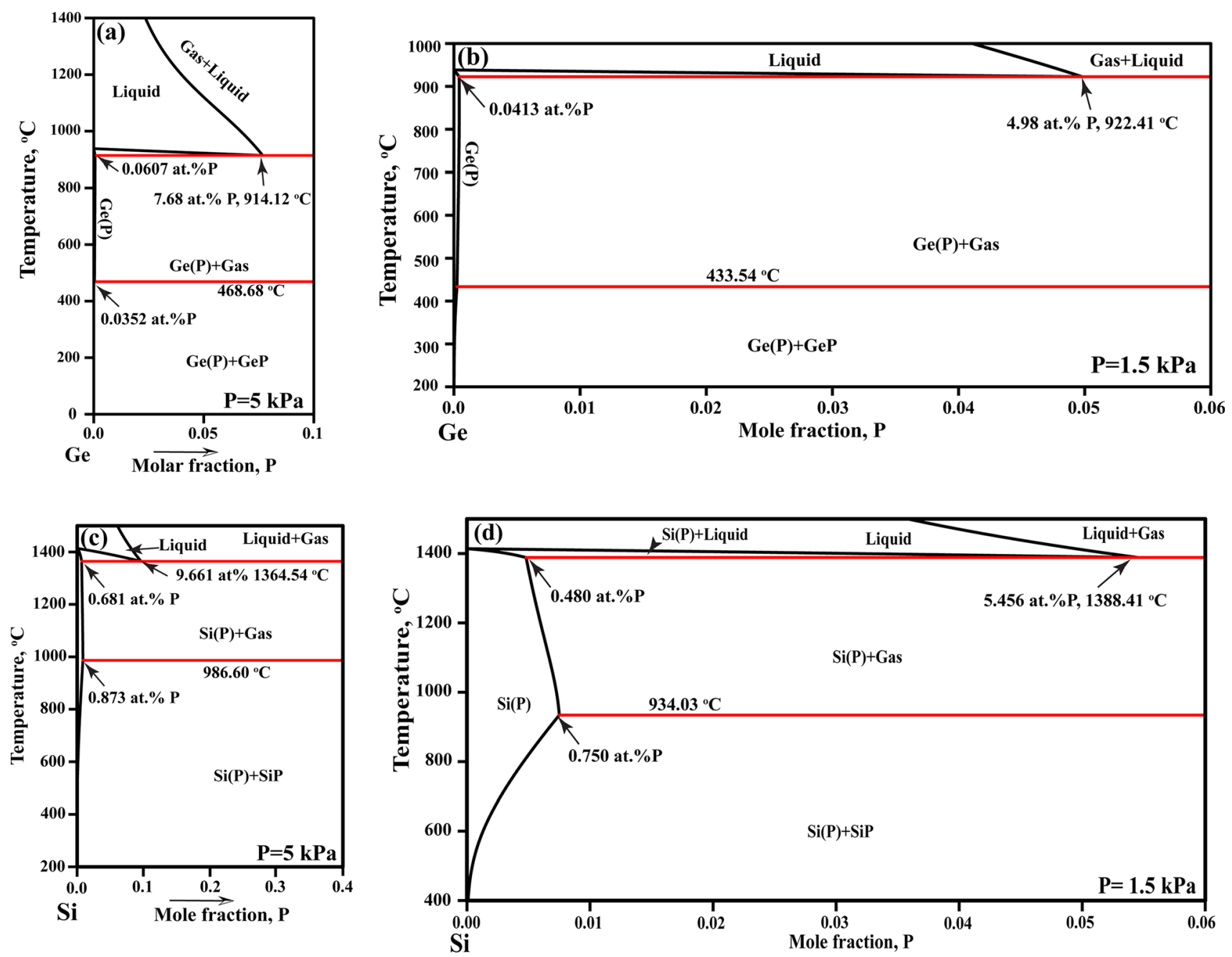

Fig. 5 Calculated Ge-rich side of the Ge-P phase diagram at $5 \mathrm{kPa}$ (a) and $1.5 \mathrm{kPa}(\mathrm{b})$, as well as calculated Si-rich side of the Si-P phase diagram at $5 \mathrm{kPa}(\mathrm{c})$ and $1.5 \mathrm{kPa}(\mathrm{d})$. Here $\mathrm{Ge}(\mathrm{P})$ and $\mathrm{Si}(\mathrm{P})$ represent

$\varepsilon=\Delta a / a_{\mathrm{Si}}=\beta X_{\mathrm{P}}$

Here $\Delta a$ is the modified lattice constant with increasing dopant concentration, $a_{\mathrm{Si}}$ is the lattice constant of undoped $\mathrm{Si}(0.5431 \mathrm{~nm})$. For dopants occupying the substitutional sites, the solute lattice contraction $(+)$ or expansion $(-)$ coefficient $\beta$ is determined by the covalent radii of dopants $\left(r_{\text {dopant }}\right)$ and that of $\mathrm{Si}\left(r_{\mathrm{Si}}\right)$, as well as the number of $\mathrm{Si}$ atoms per $\mathrm{cm}^{3}\left(X_{\mathrm{Si}} \text { is } 5 \times 10^{22} \text { atom } / \mathrm{cm}^{3}\right)^{13}$

$\beta=\frac{1}{3}\left[1-\left(\frac{r_{\text {dopant }}}{r_{\mathrm{Si}}}\right)^{3}\right] \frac{1}{X_{\mathrm{Si}}}$

The covalent radii of $\mathrm{Ge}, \mathrm{P}$ and $\mathrm{Si}$ are: $0.122 \mathrm{~nm}$, $0.11 \mathrm{~nm}, 0.1173 \mathrm{~nm}$, respectively. ${ }^{12,13,16}$ The coefficients $\beta$ of $\mathrm{Ge}$ and $\mathrm{P}$ in $\mathrm{Si}$ are hereby obtained: $\beta_{\mathrm{P}}$ is around $1.17 \times 10^{-24} \mathrm{~cm}^{3} /$ atom, and $\beta_{\mathrm{Ge}}$ is the solid solution phase of Ge_diamond and Si_diamond in Ge-P and Si-P binary system, respectively.

around $-8.91 \times 10^{-25} \mathrm{~cm}^{3} /$ atom. Using these coefficients of $\beta$, the concentration of $\mathrm{Ge}$ that is required to compensate the lattice strain introduced by $1.65 \times 10^{20}$ atoms/ $\mathrm{cm}^{3} \mathrm{P}$ in Si can be derived via $X_{\mathrm{Ge}} \beta_{\mathrm{Ge}}=X_{\mathrm{P}} \beta_{\mathrm{P}}$. Here, the required concentration of $\mathrm{Ge}$ is around $2.17 \times 10^{20}$ atoms/ $\mathrm{cm}^{3}$ (or around 0.45 at.\%, referring to Eq. 6).

Using the extrapolated thermodynamic database of Ge-P-Si ternary system, isopleth along 0.33 at.\% $\mathrm{P}$ at Sirich side of $\mathrm{Si}_{99.67} \mathrm{P}_{0.33}-\mathrm{Ge}_{99.67} \mathrm{P}_{0.33}$ (at.\%) has been calculated. As presented in Fig. 6a, at constant $\mathrm{P}$ doping level (0.33 at.\%) the solidification temperatures of the $\mathrm{Si}(\mathrm{Ge}$, P) ternary alloys decreased with increasing Ge contents. For instance, a slightly lower solidification temperature $\left(1394.25^{\circ} \mathrm{C}\right.$ ) was obtained for $\mathrm{SiGe}_{0.45} \mathrm{P}_{0.33}$ comparing with that of the binary alloy $\operatorname{SiP}_{0.33}\left(1399.95^{\circ} \mathrm{C}\right)$. In addition, the single phase boundaries of $\mathrm{Si}(\mathrm{Ge}, \mathrm{P})$ in the 
Table III Thermodynamic parameters obtained in this work

\begin{tabular}{|c|c|}
\hline Defined functions and phases notation & Parameters \\
\hline Liquid: (Ge, P, Si) & $\begin{array}{l}L_{\mathrm{Ge}, \mathrm{P}}^{0, \mathrm{Liq}}=+6072.19334 \\
L_{\mathrm{Ge}, \mathrm{P}}^{1, \mathrm{Liq}}=-1934.50901 \\
L_{\mathrm{Ge}, \mathrm{P}}^{2, \mathrm{Liq}}=+1832.59877 \\
L_{\mathrm{Si}, \mathrm{P}}^{0, \mathrm{Liq}}=-46554.9965+20.649 \cdot T \\
L_{\mathrm{Si}, \mathrm{P}}^{1, \mathrm{Piq}}=+4361.9054\end{array}$ \\
\hline Diamond: (Ge, P, Si) & $\begin{array}{l}G_{\mathrm{P}}^{\mathrm{Dia}}=+43106.57+2.092 \cdot T+G_{\mathrm{P}}^{\mathrm{White}} \\
L_{\mathrm{Ge}, \mathrm{P}}^{0, \text { Dia }}=-20127.5383+22.5340702 \cdot T \\
L_{\mathrm{Ge}, \mathrm{P}}^{1, \text { Dia }}=-1893.20478 \\
L_{\mathrm{Si}, \mathrm{P}}^{0, \text { Dia }}=-85396.4302+51.02066 \cdot T(\text { Model I }) \\
L_{\mathrm{Si}, \mathrm{P}}^{0, \text { Dia }}=+67800.6726-2.28973 \cdot T(\text { Model II }) \\
L_{\mathrm{Si}, \mathrm{P}}^{1, \text { Dia }}=+100963.105(\text { Model II }) \\
L_{\mathrm{Si}, \mathrm{P}}^{0, \text { Dia }}=+453760.054-2.38539 \cdot T(\text { Model III }) \\
L_{\mathrm{Si}, \mathrm{P}}^{1, \text { Dia }}=+489945.4(\text { Model III })\end{array}$ \\
\hline $\mathrm{GeP}:(\mathrm{Ge})_{1}(\mathrm{P})_{1}$ & $\begin{aligned} G_{\mathrm{Ge}: \mathrm{P}}^{\mathrm{GeP}}= & -40512.49493+257.5408 \cdot T-45.4 \cdot T \cdot L N(T) \\
& -0.005648 \cdot T^{2}+2.615 \cdot 10^{5} * T^{-1}\end{aligned}$ \\
\hline
\end{tabular}

Values are in SI units. Parameters assessed in present calculation are listed in the table; the other parameters were directly cited from the literature, i.e. Ge-Si from Ref. 19 and Si-P from Ref. 3. Data for pure elements are taken from SGTE (http://www.sgte.org/). isopleth also reveal that for 0.33 at. $\% \mathrm{P}$ the incorporated Ge concentration limits at 3.369 at.\%.

For a binary system, it is straight forward to get the $K_{\mathrm{eq}}$ value from the relevant phase equilibrium, i.e. $K_{\mathrm{eq}}=C_{\mathrm{L}} / C_{\mathrm{S}}$, $C_{\mathrm{L}}$ and $C_{\mathrm{S}}$ are the dopant concentrations on the liquidus and solidus lines at a given temperature. Concerning the $K_{\text {eq }}$ of $\mathrm{P}$ in $\mathrm{Si}(\mathrm{P}, \mathrm{Ge})$, phase diagram calculation works as well. Firstly, a vertical section that crosses the doping concentration of interest is calculated. The solidification temperature of that alloy is then obtained. Subsequently, a corresponding isothermal section will be calculated. The liquid composition that equilibrates with the solid can be directly taken by selecting the relevant tie-line in the liquid-solid two-phase equilibrium field (as depicted in Fig. 6b), and then the $K_{\text {eq }}$ of the dopant at his doping level (e.g. 0.33 at\% $\mathrm{P}$ in this work) and temperature is acquired. Table IV lists the $K$ values from literature and the current calculation by using the extrapolated Ge-Si-P ternary thermodynamic description.

The $K_{\text {eq }}$ values of $\mathrm{P}$ in $\mathrm{Si}$ at around melting point of $\mathrm{Si}$ obtained in this work are comparable with other theoretical data. ${ }^{3,22,58}$ However, all the calculated values are way too small than the widely accepted effective segregation coefficient $\left(K_{\text {eff }}\right.$ of 0.35). ${ }^{56}$ The reason of such difference can be partially interpreted by the well-known Barton-Prim-Slichter equation $^{63}$ and the modifications. ${ }^{4,64}$ The $K_{\text {eff }}$ is determined not only by the $K_{\text {eq }}$ but also by the concentration dependent properties of the dopants (e.g. diffusivity in melt, evaporation rate) and the process parameters (e.g. pulling rate, angular velocity of crystal rotation). In addition, the impurities of oxygen and carbon are unavoidable during $\mathrm{CZ}$ Si growth process. The dissolved oxygen impacted the solubility level of $\mathrm{P}$ in $\mathrm{Si},{ }^{65}$ as also discussed in the last section. Furthermore, the thermal donors, associated with interstitial oxygen in $\mathrm{CZ} \mathrm{Si}$ and formed during cooling process in temperature range of $400-500^{\circ} \mathrm{C}$, contribute to the free carrier concentration, ${ }^{66}$ thus influencing the accuracy derivation of dopants $K$ values via resistivity methods. The influence of oxygen on the heavily P-doped CZ Si will be exploited in another publication.

There is limited data available regarding the $K_{\text {eff }}$ of $\mathrm{P}$ in $\mathrm{Si}_{x} \mathrm{Ge}_{1-x}{ }^{16,67-69}$ Refs. 67 and 68 reported the $K_{\text {eff }}$ values of lightly P-doped Ge-rich SiGe crystal $\left(\mathrm{Si}_{0.05} \mathrm{Ge}_{0.95}\right)$; however, the $\mathrm{P}$ concentration was not specified. Yonenaga et al. ${ }^{69}$ evaluated the $K_{\text {eff }}$ of P in Si-rich CZ SiGe crystal based on (i) the carrier concentrations in the melts and the grown crystal via relation $K_{\text {eff }}=C_{\mathrm{S}} / C_{\mathrm{L}}$, or (ii) the carrier concentrations at the position of growth initiation of the crystal $\left(C_{\mathrm{S} 0}\right)$ and carrier concentration at grown $\mathrm{SiGe}$ with a solidification ratio $(f)$ of $0.5\left(C_{\mathrm{S}}\right)$ via normal freezing equation $C_{\mathrm{S}}=C_{\mathrm{S} 0} K_{\mathrm{eff}}(1-f)^{k_{\mathrm{eff}}-1} .{ }^{16}$ They reported a dramatic increase of the $K_{\text {eff }}$ (listed in Table IV). ${ }^{16}$ Those values were not without doubt since the oxygen concentration was unignorable, for instance, it was $9 \times 10^{17}$ atoms $/ \mathrm{cm}^{3}$ in their un-doped crystal. $^{16}$

In this work, the comparison with $K_{\text {eff }}$ values reported in Ref. 16 were not attempted. Instead, the $K_{\text {eq }}$ of P varying with the Ge fraction in $\mathrm{Si}_{1-x} \mathrm{Ge}_{x}$ was calculated (Fig. 7) by referring to the alloy concentrations utilized in Ref. 

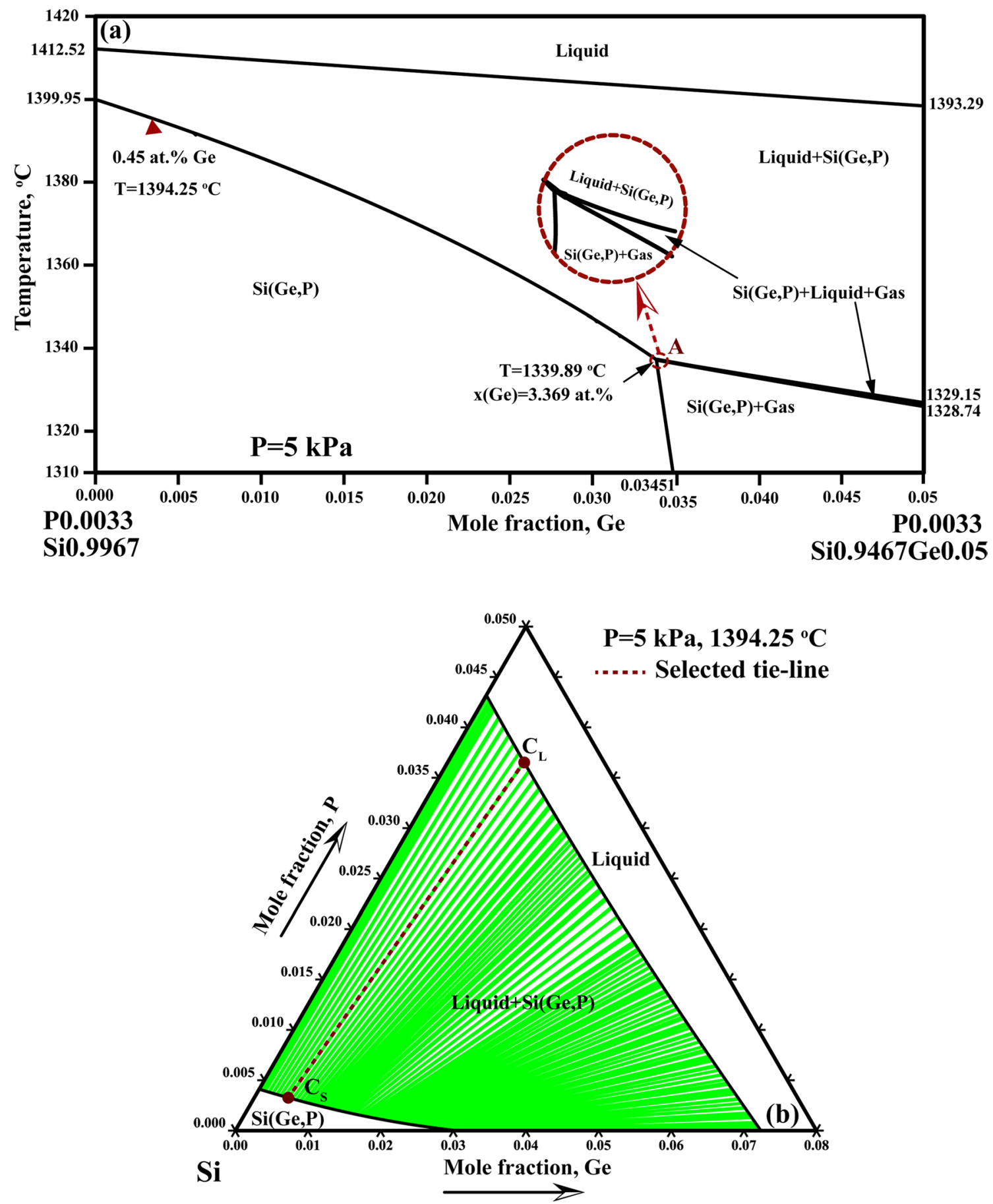

Fig. 6 Calculated phase diagram of Ge-P-Si at $5 \mathrm{kPa}$ (a) is isopleth of 0.33 at.\% $\mathrm{P}$ at Si-rich side, the region near point A was schematically illustrated in the inserted figure, and (b) is the Si-rich corner of

16. The results demonstrated that: (i) at constant $\mathrm{P}$ doping level, the $K_{\text {eq }}$ of $\mathrm{P}$ decreased with increasing Ge fraction in the $\mathrm{Si}_{1-x} \mathrm{Ge}_{x}$ crystal; (ii) at a constant Ge fraction, the higher the $\mathrm{P}$ doping level, the smaller $K_{\mathrm{eq}}$ of P one gets. As shown in Fig. 7, the $K_{\mathrm{eq}}$ values of $\mathrm{P}$ are greatly dependent on the Ge fraction. It is observed that the $K_{\mathrm{eq}}$ value of $\mathrm{P}$ the isothermal section of $\mathrm{Si}-\mathrm{Ge}-\mathrm{P}$ at $1393.98^{\circ} \mathrm{C}, 5 \mathrm{kPa}$. Here $\mathrm{Si}(\mathrm{Ge}$, $\mathrm{P})$ is the Si_diamond solid solution phase that has certain solubility of both Ge and P.

in $\mathrm{Si}(\mathrm{P}, \mathrm{Ge})$ can increase with increasing $\mathrm{P}$ concentration as long as Ge fraction changes accordingly, for instance, under the condition that $\mathrm{x}(\mathrm{Ge})$ is less than 0.043 at the $\mathrm{P}$ doping level of $6 \times 10^{19}$ atoms $/ \mathrm{cm}^{3}$, and $\times(\mathrm{Ge})$ is higher than 0.046 at the $\mathrm{P}$ doping level of $8 \times 10^{17}$ atoms $/ \mathrm{cm}^{3}$. 
Table IV Segregation coefficients of $\mathrm{P}$ in $\mathrm{Si}$, and $\mathrm{SiGe}$ crystal

\begin{tabular}{|c|c|c|c|}
\hline \multicolumn{2}{|c|}{$\mathrm{K}_{\mathrm{eq}}^{\mathrm{a}}$ or $\mathrm{K}_{\mathrm{eff}}^{\mathrm{b}}$ of $\mathrm{P}$ in $\mathrm{Si}$} & \multirow{2}{*}{$\begin{array}{l}\text { Applied measurement method } \\
\text { Four undetailed methods: Conductivity measurements, melting and recrystallization of a } \\
\text { doped crystal, measurement of the impurity content as a function of distance along the } \\
\text { crystal, and radioactive tracers }\end{array}$} & \multirow{2}{*}{$\frac{\text { Ref. }}{70}$} \\
\hline $\mathrm{P}$ in $\mathrm{Si}$ & $0.04^{\mathrm{a}}$ & & \\
\hline & $0.35^{\mathrm{a}}$ & Radiochemical analysis and conductivity measurements & 71 \\
\hline & $0.35^{\mathrm{b}}$ & $\begin{array}{l}\text { Radiochemical analysis. Evaporation of P during crystal growth were ignored, CZ growth } \\
\text { crystal }\end{array}$ & 72 \\
\hline & $0.35^{\mathrm{a}}$ & Evaluation, widely cited & 56 \\
\hline & $0.42^{\mathrm{b}}$ & Electrical resistivity, Pulling rate: 1.8 mils/s, $\mathrm{CZ}$ growth crystal & 73 \\
\hline & $0.32^{\mathrm{b}}$ & Electrical resistivity, Pulling rate: $1.0 \mathrm{mils} / \mathrm{s}, \mathrm{CZ}$ growth crystal & \\
\hline & $0.35^{\mathrm{b}}$ & $\begin{array}{l}\text { Spark source mass spectroscopy and/or neutron activation analysis for doping concen- } \\
\text { tration in } \mathrm{Si} \text { ingot }\left(\mathrm{C}_{\mathrm{S}}\right) \text {, and emission spectroscopy or atomic absorption for dopants } \\
\text { concentration in residual melt of growth }\left(\mathrm{C}_{\mathrm{L}}\right) \text {. CZ growth crystal }\end{array}$ & 74 \\
\hline & $0.123^{\mathrm{a}}$ & Calculated, experimental data by Hall measurement & 58 \\
\hline & $0.09^{\mathrm{a}}$ & Phase diagram, measured & 22 \\
\hline & $0.038^{\mathrm{a}}$ & Phase diagram, thermodynamic calculation, Model I & 3 \\
\hline & $0.157^{\mathrm{a}}$ & Phase diagram, thermodynamic calculation, Model III, at $100 \mathrm{kPa}$ & This work \\
\hline & $0.156^{\mathrm{a}}$ & Phase diagram, thermodynamic calculation, Model III, at $5 \mathrm{kPa}$ & \\
\hline \multirow[t]{3}{*}{$\mathrm{P}$ in $\mathrm{SiGe}$} & $0.8, \sim 0.6,0.9-1^{\mathrm{b}}$ & $\begin{array}{l}\text { Hall effect measurements, heavily doping up to } 10^{20} \text { atoms } / \mathrm{cm}^{3} \text {, no exact data given, } \mathrm{CZ} \\
\text { crystal, Ar flow, } 100 \mathrm{kPa} \text {. } K \text { correspond to } \mathrm{Si}_{1-x} \mathrm{Ge}_{x} \text {, with } x=0.2,0.1,0.05\end{array}$ & 69 \\
\hline & $0.31,0.76^{\mathrm{b}}$ & $\begin{array}{l}\text { Hall measurements, P concentrations at the position of growth initiation }\left(8 \times 10^{17} \text { and }\right. \\
\left.6 \times 10^{19} \text { atoms } / \mathrm{cm}^{3}\right), \mathrm{CZ} \text { growth crystal, Ar flow, } 100 \mathrm{kPa}\end{array}$ & 16 \\
\hline & $0.093^{\mathrm{b}}$ & $\begin{array}{l}\text { Resistance measurements, } \mathrm{P} \text { (unknown doping level) in crystal } \mathrm{Si}_{x} \mathrm{Ge}_{1-x}(x=0.05) \text {. Verti- } \\
\text { cal Bridgman method and Zone melting }\end{array}$ & 67,68 \\
\hline \multirow[t]{4}{*}{$\mathrm{Ge}-\mathrm{P}$ in $\mathrm{Si}$} & $0.1045^{\mathrm{a}}$ & Co-doping level: 0.33 at. $\% \mathrm{P}+0$ at. $\% \mathrm{Ge}$, at $5 \mathrm{kPa}$ and $1399.95^{\circ} \mathrm{C}$ & Calculated, this work \\
\hline & $0.0933^{\mathrm{a}}$ & Co-doping level: 0.33 at. $\% \mathrm{P}+0.33$ at. $\% \mathrm{Ge}$, at $5 \mathrm{kPa}$ and $1395.82^{\circ} \mathrm{C}$ & \\
\hline & $0.0895^{\mathrm{a}}$ & Co-doping level: 0.33 at. $\% \mathrm{P}+0.45$ at. $\% \mathrm{Ge}$, at $5 \mathrm{kPa}$ and $1394.25^{\circ} \mathrm{C}$ & \\
\hline & $0.0824^{\mathrm{a}}$ & Co-doping level: 0.33 at. $\% \mathrm{P}+0.69$ at. $\% \mathrm{Ge}$, at $5 \mathrm{kPa}$ and $1391.01^{\circ} \mathrm{C}$ & \\
\hline
\end{tabular}

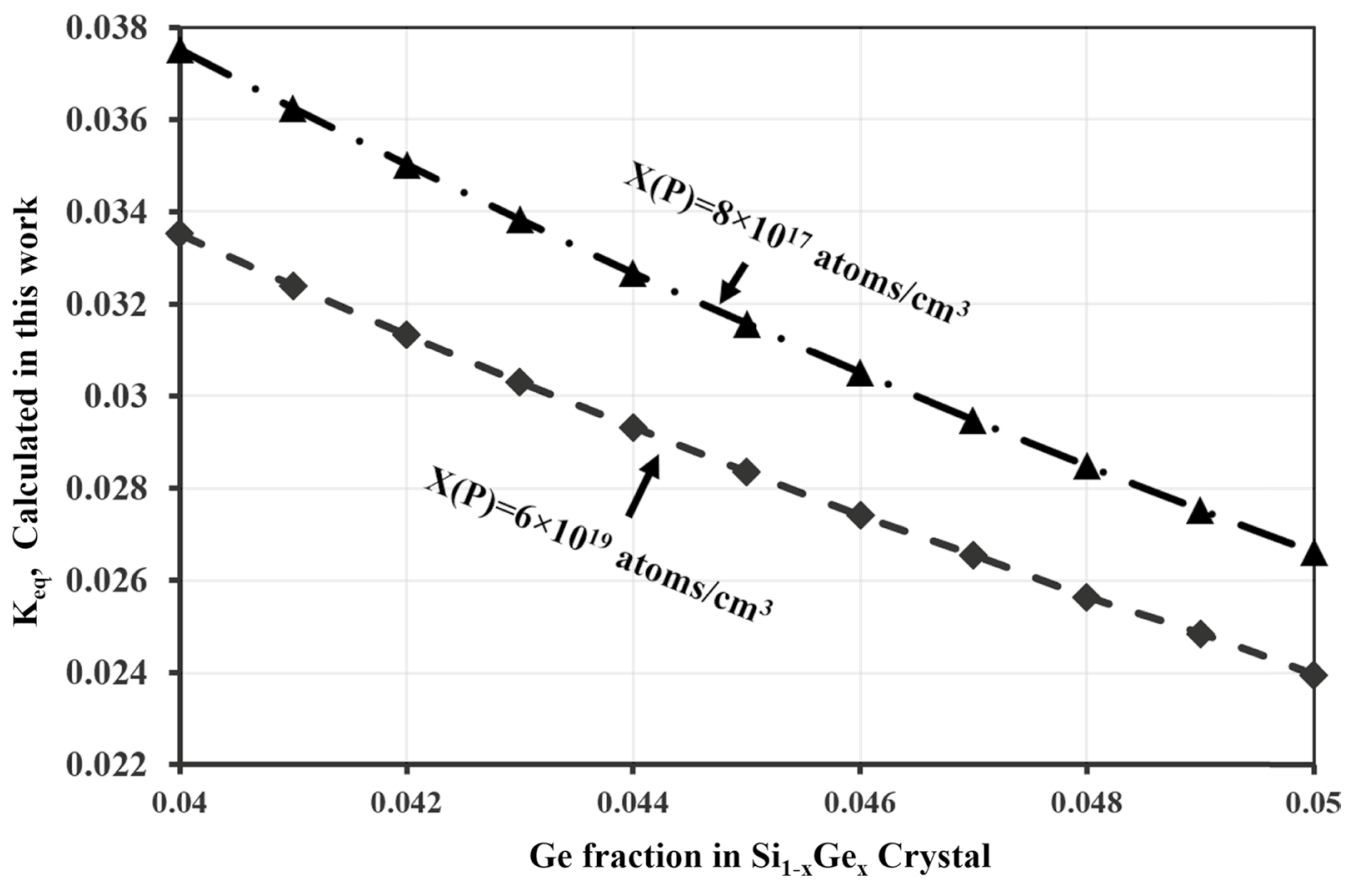

Fig. 7 Calculated equilibrium segregation coefficient of $\mathrm{P}$ at concentration of $6 \times 10^{19}$ atoms $/ \mathrm{cm}^{3}$ and $8 \times 10^{17}$ atoms $/ \mathrm{cm}^{3} \mathrm{dependent}$ on the Ge fraction in $\mathrm{Si}_{1-x} \mathrm{Ge}_{x}$. 
The $K_{\text {eq }}$ values of P (0.33 at.\%) with respect to different Ge co-doping level were theoretically calculated using the currently extrapolated Ge-P-Si thermodynamic database. The relevant solidification temperatures were directly read from the isopleth of 0.33 at.\% P (Fig. 6a). At this P doping level (0.33 at.\%), the $K_{\text {eq }}$ values of $\mathrm{P}$ in $\mathrm{Si}(\mathrm{P}, \mathrm{Ge})$ decreased with increasing $\mathrm{Ge}$ co-doping concentrations.

\section{Impacts on P Distribution in Si Matrix}

To understand the role of $\mathrm{Ge}$ in $\mathrm{P}$ distribution in the $\mathrm{Si}$ matrix, the current DFT calculations simulated the monovacancy formation energy of un-doped $\mathrm{Si}$, the formation energy of substitutional $\mathrm{Si}(\mathrm{P})$ and $\mathrm{Si}(\mathrm{Ge})$ solutions, as well as the binding energies of two like (P-P, Ge-Ge) and dislike (Ge-P) dopants positioning as $1 \mathrm{NN}, 2 \mathrm{NN}$ and $3 \mathrm{NN}$ in the Si matrix. Generally, the formation energy can be derived from the equation:

$E_{\text {formation }}=E_{\text {products }}-E_{\text {reactants }}$

Accordingly, the vacancy formation energy of $\mathrm{Si}$ without solute atoms $\Delta E_{f}^{V}$ is determined by the energy difference of the perfect structure and that of monovacancy:

$\Delta E_{f}^{\mathrm{SiVa}_{1}}=E_{\mathrm{Si}_{N-1} \mathrm{Va}_{1}}-\frac{N-1}{N} E_{\mathrm{Si}_{N}}$

where $N$ is the total atoms in the supercells, $\mathrm{Va}_{1}$ indicates one vacancy on the Si lattice site. $E_{\mathrm{Si}_{N-1} \mathrm{Va}_{1}}$ and $E_{\mathrm{Si}_{N}}$ correspond to the total energy of the supercell including one vacancy and that of perfect cell.

The formation reaction for the Si-based solid solution with substitutional dopants is:

$N \mathrm{Si}+1 X=\mathrm{Si}_{N-1} \mathrm{X}_{1}+1 \mathrm{Si}$

One can obtain the substitutional formation energy of a single dopant in Si matrix:

$\Delta E_{f}^{\mathrm{SiX}_{1}}=E_{\mathrm{Si}_{N-1} X_{1}}-\frac{N-1}{N} E_{\mathrm{Si}_{N}}-1 \cdot E_{X}$

Here, $E_{\mathrm{Si}_{N-1} X_{1}}$ is the total energy of the cell including one dopant, and $E_{X}$ is the energy of an isolated dopant atom. Table $\mathrm{V}$ summarizes the formation energies derived from total energies obtained by using GGA exchange-correlation potential. The monovacancy formation in Si obtained in this work is comparable with data from previous DFT studies, ${ }^{75,76}$ i.e. at $0 \mathrm{~K}$ for the neutral vacancy, $\Delta E_{f}^{\mathrm{SiVa}_{1}}$ is in the range of 3.4-4.4 eV. Therefore, the reliability of current calculation was verified. Values listed in Table $\mathrm{V}$ show that of the calculated formation energy of the $\mathrm{Si}(\mathrm{Ge})$ substitutional solution is less than that of $\mathrm{Si}(\mathrm{P})$. It implies a higher tendency to form the $\mathrm{Si}(\mathrm{Ge})$ solution phase than
Table V Formation energy for monovacancy in $\mathrm{Si}$, and Si-based solid solution with $\mathrm{P}$ and $\mathrm{Ge}$

\begin{tabular}{lll}
\hline Formation energy & $\begin{array}{l}\text { 64-atom supercell, } \\
\text { unit: } \mathrm{eV}\end{array}$ & $\begin{array}{l}\text { 216-atom } \\
\text { supercell, } \\
\text { unit: eV }\end{array}$ \\
\hline$\Delta E_{f}^{\mathrm{SiVa}_{1}}$ & 3.6448 & 3.8690 \\
$\Delta E_{f}^{\mathrm{SiGe}_{1}}$ & 0.0837 & 0.0701 \\
$\Delta E_{f}^{\mathrm{SiP}_{1}}$ & 0.2557 & 0.2023 \\
\hline
\end{tabular}

Table VI Calculated binding energies in this work

\begin{tabular}{lll}
\hline Binding energy & $\begin{array}{l}\text { 64-atom supercell, unit: } \\
\mathrm{eV}\end{array}$ & $\begin{array}{l}\text { 216-atom } \\
\text { supercell, unit: } \\
\mathrm{eV}\end{array}$ \\
\hline$\Delta E_{b}^{1 \mathrm{NN}}(\mathrm{GeGe})$ & -0.0122 & 0.0016 \\
$\Delta E_{b}^{2 \mathrm{NN}}(\mathrm{GeGe})$ & 0.0040 & 0.0184 \\
$\Delta E_{b}^{3 \mathrm{NN}}(\mathrm{GeGe})$ & - & 0.0144 \\
$\Delta E_{b}^{1 \mathrm{NN}}(\mathrm{PP})$ & 0.0409 & 0.1238 \\
$\Delta E_{b}^{2 \mathrm{NN}}(\mathrm{PP})$ & 0.1005 & 0.1985 \\
$\Delta E_{b}^{3 \mathrm{NN}}(\mathrm{PP})$ & - & 0.1120 \\
$\Delta E_{b}^{1 \mathrm{NN}}(\mathrm{GeP})$ & -0.0009 & 0.0067 \\
$\Delta E_{b}^{2 \mathrm{NN}}(\mathrm{GeP})$ & 0.0073 & 0.0128 \\
$\Delta E_{b}^{3 \mathrm{NN}}(\mathrm{GeP})$ & - & 0.0194 \\
\hline
\end{tabular}

to form the $\mathrm{Si}(\mathrm{P})$ solution phase, which is supported by the significantly larger solubility of Ge in Si solid phase comparing with that of $P$.

The binding energy for two substitutional solute dopant atoms in $\mathrm{Si}$ is obtained from:

$\Delta E_{b}^{\mathrm{iNN}}\left(X_{1} X_{2}\right)=E_{\mathrm{Si}_{N}}+E_{\mathrm{Si}_{N-2} X_{1} X_{2}}-E_{\mathrm{Si}_{N-1} X_{1}}-E_{\mathrm{Si}_{N-1} X_{2}}$

In Eq. 13, iNN denotes the 1st to 3rd nearest neighbors. $X_{1}$ and $X_{2}$ are the substitutional dopant atom Ge and $\mathrm{P}$. Table VI lists the binding energies of P-P, Ge-Ge and Ge-P derived by following Eq. 13. The binding energy between $\mathrm{Ge}$ and $\mathrm{Ge}$ atoms at the $1 \mathrm{NN}$ position is smaller than the binding energies of $\mathrm{Ge}-\mathrm{Ge}$ at $2 \mathrm{NN}$ and $3 \mathrm{NN}$ positions. It is apparent that $\mathrm{Ge}$ atoms tend to gather in the $\mathrm{Si}$ matrix. Examining the results of the binding energies of $\mathrm{Ge}-\mathrm{P}$ bonds, one can notice that Ge-P bonds distributing at $1 \mathrm{NN}$ and $2 \mathrm{NN}$ positions are more energetically favorable than at $3 \mathrm{NN}$; however, for P-P bonds the opposite tendency is observed. In addition, binding energies of P-P bonds are higher than those of Ge-P and Ge-Ge bonds for each level of neighboring bonds position. This suggests that the $\mathrm{P}$ atoms are energetically favorable to interact with $\mathrm{Ge}$ atoms rather than to cluster in the $\mathrm{Si}$ matrix. The Ge co-doping in $\mathrm{P}$-doped Si can then provide the drag-and-drop effect, and thus to homogenize the P distribution in Si solid. 

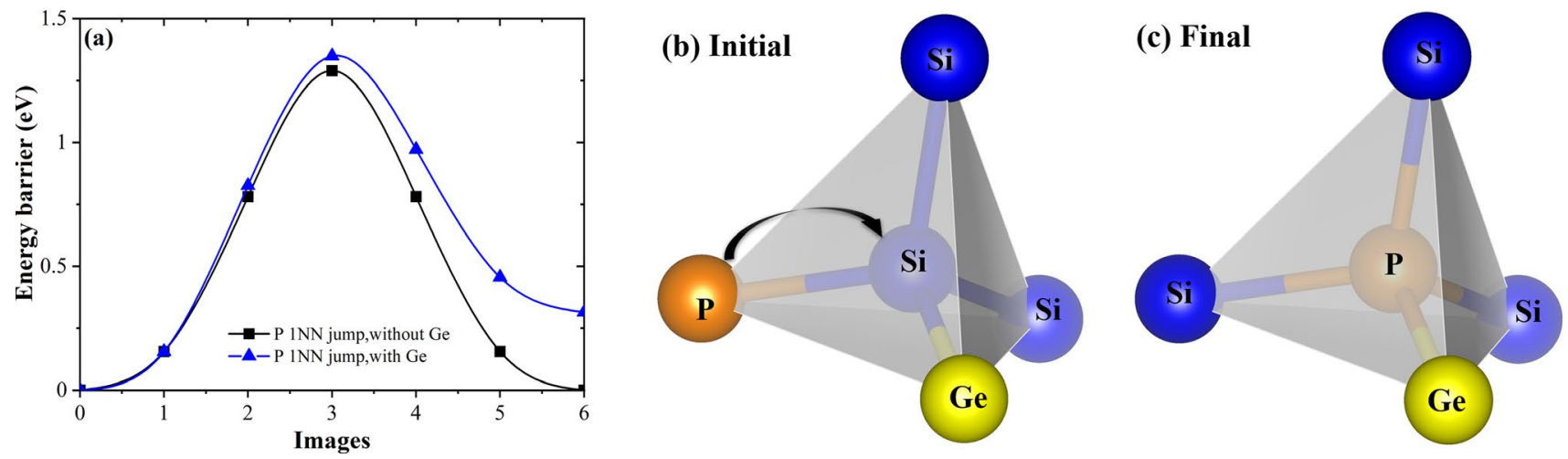

Fig. 8 DFT NEB calculation for P atom 1NN jump in Si crystal (a), as well as the schematic graph of initial of P atom (b) and the final stages of $\mathrm{P}$ atom migration along the $1 \mathrm{NN}$ bond where Ge occupying one of the other $1 \mathrm{NN}$ neighbor (c).

$\mathrm{P}$ diffusion in Si poses a technological difficulty in forming well-defined doped regions for devices. In order to check the impact of $\mathrm{Ge}$ on the migration of $\mathrm{P}$ atoms in the Si matrix, the CL-NEB calculations were performed to simulate the migration barriers for a $1 \mathrm{NN} P$ jump in the 64-atom Si cubic supercell. The calculations were executed with/without a Ge atom occupying a site that also forms the nearest neighbor bond with the same corner atom as $\mathrm{P}$ neighboring. The barrier energies of the $\mathrm{P}$ diffusion between $1 \mathrm{NN}$ position are depicted in Fig. 8a. The migration of $\mathrm{P}$ atoms in the Si matrix is illustrated in Fig. 8b. Curves in Fig. 8a demonstrates that the barrier energy of $\mathrm{P}$ diffusion with Ge presented is larger than that of the case without involving $\mathrm{Ge}$, which is in agreement with previous experimental research on stability of the P-Va pair in n-doped $\mathrm{Si}_{1-x} \mathrm{Ge}_{x}{ }^{77}$ This justifies our conclusion that Ge co-doping can slow $\mathrm{P}$ diffusion in Si solid.

\section{Conclusion}

This work investigated the Ge influence on the P distribution in $\mathrm{Si}$ based on thermodynamic considerations by analyzing results from CALPHAD approaches and DFT calculations. Phase diagrams of Ge-P and Si-P binary systems were thermodynamically re-assessed. Thermodynamic description of the Si-P-Ge ternary system has thus been theoretically extrapolated. It was then utilized to calculate the isopleth diagram of $\mathrm{SiP}_{x}-\mathrm{GeP}_{x}(x=0.33$ at.\%) and isothermal sections of Si-Ge-P at $5 \mathrm{kPa}$. Accordingly, the Ge impacts on the solidification temperature and $K_{\text {eq }}$ of $\mathrm{P}$ in doped $\mathrm{Si}$ have been studied based on the calculated diagrams. It was found that at constant $\mathrm{P}$ concentration $(0.33$ at.\%) the solidification temperature of $\mathrm{Si}(\mathrm{Ge}, \mathrm{P})$ decreased with increasing Ge concentration, so did the $K_{\text {eq }}$ of P. DFT calculations performed on the formation energy for monovacancy of Si crystal and substitutional Si-dopant solutions, i.e. $\mathrm{Si}(\mathrm{Ge})$ and $\mathrm{Si}(\mathrm{P})$, and the binding energy of $\mathrm{P}-\mathrm{P}, \mathrm{Ge}-\mathrm{Ge}$ and Ge-P bonds loacted at $1 \mathrm{NN}, 2 \mathrm{NN}$ and $3 \mathrm{NN}$ positions. Comparing with P-P bonds, both $\mathrm{Ge}-\mathrm{Ge}$ and Ge-P bonds have larger binding energy at all the three configurations. The energy barriers of $\mathrm{P}$ migration between the $1 \mathrm{NN}$ bond were calculated by DFT-NEB. The higher energy barriers were obtained when neighbored by a $\mathrm{Ge}$ atom than that without Ge occupying a site of another1NN bond. These results led to the conclusion that in heavily P-doped Si, Ge does not have the capability to improve the even distribution of $\mathrm{P}$ along the $\mathrm{Si}$ ingot during crystal growth process, nevertheless, Ge co-doping in the solid state of the P-doped Si crystal can reduce the $\mathrm{P}$ atoms gathering and its diffusion in $\mathrm{Si}$ and thus to stabilize the P-doped Si structure.

Acknowledgments This work is part of the POSITION-II project funded by the ECSEL Joint Undertaking under grant number Ecsel783132-Position-II-2017-IA. www.position-2.eu. The authors would like to acknowledge the Innovation Funding Agency Business Finland for their financial support. Dr. Jari Paloheimo and Dr. Heikki Holmberg from Okmetic Oy, Finland, are acknowledged for useful discussions. One of the authors, Dr. Xiaoma Tao, acknowledges the support from National Natural Science Foundation of China [Grants Nos. 51661003 and 51961007], and the Guangxi Natural Science Foundation [Grant No. 2018GXNSFAA281254].

Funding Open access funding provided by Aalto University.

Conflict of interest The authors declare that they have no conflict of interest.

Open Access This article is licensed under a Creative Commons Attribution 4.0 International License, which permits use, sharing, adaptation, distribution and reproduction in any medium or format, as long as you give appropriate credit to the original author(s) and the source, provide a link to the Creative Commons licence, and indicate if changes were made. The images or other third party material in this article are included in the article's Creative Commons licence, unless indicated otherwise in a credit line to the material. If material is not included in the article's Creative Commons licence and your intended use is not 
permitted by statutory regulation or exceeds the permitted use, you will need to obtain permission directly from the copyright holder. To view a copy of this licence, visit http://creativecommons.org/licenses/by/4.0/.

\section{References}

1. M. Tilli, M. Paulasto-Krockel, M. Petzold, H. Theuss, T. Motooka, and V. Lindroos, Handbook of silicon based MEMS materials and technologies, 3rd ed. (Amsterdam: Elsevier, 2020), p. 19.

2. I.H. Jung and Y. Zhang, JOM 64, 973 (2012).

3. S.M. Liang and R. Schmid-Fetzer, J. Phase. Equilibria. Diffus. 35, 24 (2014).

4. M. Porrini, R. Scala, and V.V. Voronkov, J. Cryst. Growth 460, 13 (2017).

5. G.L. Pearson and J. Bardeen, J. Phys. Rev. 75, 865 (1949).

6. K.D. Weeks, S.G. Thomas, P. Dholabhai, and J. Adams, Thin Solid Films 520, 3158 (2012).

7. M. Lee, H.Y. Ryu, E. Ko, and D.H. Ko, ACS Appl. Electron. Mater. 1, 288 (2019).

8. J.R. Carruthers, R.B. Hoffman, and J.D. Ashner, J. Appl. Phys. 34, 3389 (1963).

9. H.D. Chiou, J. Electrochem. Soc. 147, 345 (2000).

10. S. Kawazoe, Y. Narushima, T. Kubota, and F. Ogawa, Process for production of silicon single crystal, and highly doped N-type semiconductor substrate. U.S. Patent No. 8,747,551. Washington, DC: U.S. Patent and Trademark Office, 2014-6-10.

11. G. Celotti, D. Nobili, and P. Ostoja, J. Mater. Sci. 9, 821 (1974).

12. Y. Okada, Properties of crystalline silicon, ed. R. Hull (London: INSPEC, 1999), p. 91.

13. Y.T. Lee, N. Miyamoto, and J. Nishizawa, J. Electrochem. Soc. 122, 530 (1975)

14. J. Vanhellemont, J. Chen, J. Lauwaert, H. Vrielinck, W. Xu, D. Yang, J.M. Rafí, H. Ohyama, and E. Simoen, J. Cryst. Growth 317, 8 (2011)

15. I. Yonenaga, Jpn. J. Appl. Phys. 45, 2678 (2006).

16. I. Yonenaga and T. Ayuzawa, J. Cryst. Growth 297, 14 (2006).

17. R.W. Olesinski and G.J. Abbaschian, Bull. Alloy Phase Diagrams. 5, 180 (1984).

18. C. Bergman, R. Chastel, and R. Castanet, J. Phase Equilib. 13, 113 (1992)

19. SGTE Solutions Database Version 4.9 (SSOL4).

20. R.W. Olesinski, N. Kanani, and G.J. Abbaschian, Bull. Alloy Phase Diagrams 6, 130 (1985).

21. K. Tang, E.J. Øvrelid, G. Tranell, and M. Tangstad, in Crystal Growth of Si for Solar Cells, ed. by K. Nakajima and N. Usami (Springer, Berlin 2009), p. 219.

22. J. Safarian and M. Tangstad, J. Mater. Res. 26, 1494 (2011).

23. N.A. Arutyunyan, A.I. Zaitsev, and N.G. Shaposhnikov, Russ. J. Phys. Chem. A 85, 911 (2011).

24. E.G. Goncharov, L.I. Sokolov, and Y.A. Ugai, Zh. Neorg. Khim. 20, 2452 (1975).

25. Y.A. Ugai, L.I. Sokolov, E.G. Goncharov, and V.R. Pshestanchik, Russ. J. Inorg. Chem. 23, 1048 (1978).

26. N.K. Abrikosov, V.M. Glazov, and C.Y. Liu, Russ. J. Lnorg. Chem. 7, 429 (1962).

27. V.I. Fistul, A.G. Yakovenko, A.A. Gvelesiani, V.N. Tsy-gankov, and R.L. Korchazhkina, Izv. Akad. Nauk SSSR Neorg. Mater. 11, 539 (1975)

28. N.D. Zakharov, V.N. Rozhanskij, and R.L. Korchazhkina, Fiz. Tverd. Tela. 16, 1444 (1974).

29. M. Zumbusch, M. Heimbrecht, and W. Biltz, Z. Anorg. Allg. Chem. 242, 237 (1939).

30. B. Süess, K. Hein, and J. Korb, Z. Anorg. Allg. Chem. 494, 115 (1982).
31. Y.A. Ugai, A.F. Demidenko, V.I. Koshchenko, V.E. Yachmenev, L.I. Sokolov, and E.G. Goncharov, Inorg. Mater. 15, 578 (1979).

32. I. Barin, O. Knacke, and O. Kubaschewski, Thermochemical Properties of Inorganic Substances (Supplement), 1st ed. (Berlin: Springer, 1977), p. 293.

33. O. Knacke, O. Kubaschewski, and K. Hesselmann, Thermochemical properties of Inorganic Substance, 2nd ed. (Berlin: Springer, 1991).

34. M. Binnewies and E. Milke, Thermochemical Data of Elements and Compounds, 2nd ed. (Weinheim: Wiley-VCH, 1999), p. 261.

35. D.R. Lide, in CRC Handbook of Chemistry and Physics (CRC Press, Boca Raton, FL, Internet Version, 2005), p. 5.

36. M.E. Schlesinger, Chem. Rev. 102, 4267 (2002).

37. S. Kirklin, J.E. Saal, B. Meredig, A. Thompson, J.W. Doak, M. Aykol, S. Rühl, and C. Wolverton, Npj Comput. Mater. 1, 15010 (2015).

38. A. Jain, S.P. Ong, G. Hautier, W. Chen, W.D. Richards, S. Dacek, S. Cholia, D. Gunter, D. Skinner, G. Ceder, and K.A. Persson, APL Mater. 1, (2013).

39. S. Curtarolo, W. Setyawan, G.L.W. Hart, M. Jahnatek, R.V. Chepulskii, R.H. Taylor, S. Wang, J. Xue, K. Yang, O. Levy, M.J. Mehl, H.T. Stokes, D.O. Demchenko, and D. Morgan, Comput. Mater. Sci. 58, 218 (2012).

40. R.W. Olesinski, N. Kanani, and G.J. Abbaschian, Bull. Alloy Phase Diagrams 6, 262 (1985).

41. A.T. Dinsdale, Calphad 15, 317 (1991)

42. J.O. Andersson, T. Helander, L. Höglund, P.F. Shi, and B. Sundman, Calphad 26, 273 (2002).

43. M. Hillert, Calphad 4, 1 (1980).

44. P. Chartrand and A.D. Pelton, J. Phase Equilib. 21, 141 (2000).

45. A.D. Pelton, Calphad 25, 319 (2001).

46. H. Lukas, S.G. Fries, and B. Sundman, Computational Thermodynamics: The Calphad Method, 1st ed. (Cambridge: Cambridge University Press, 2007), p. 112.

47. T. Wadsten, Acta Chem. Scand. 21, 593 (1967).

48. K. Lee, S. Synnestvedt, M. Bellard, and K. Kovnir, J. Solid State Chem. 224, 62 (2015).

49. P.E. Blöchl, Phys. Rev. B 50, 17953 (1994).

50. G. Kresse and D. Joubert, Phys. Rev. B 59, 1758 (1999)

51. G. Kresse and J. Furthmüller, Phys. Rev. B 54, 11169 (1996).

52. G. Kresse and J. Furthmüller, Comput. Mater. Sci. 6, 15 (1996).

53. G. Henkelman, B.P. Uberuaga, and H. Jonsson, J. Chem. Phys. 113, 9901 (2000).

54. G. Henkelman and H. Jonsson, J. Chem. Phys. 113, 9978 (2000).

55. B. Giessen and R. Vogel, Z. Metallkd. 50, 274 (1959).

56. F.A. Trumbore, Bell Syst. Tech. J. 39, 205 (1960).

57. E. Kooi, J. Electrochem. Soc. 111, 1383 (1964).

58. V.E. Boeisenko and S.G. Yudin, Phys. Status Solidi A 101, 123 (1987).

59. D. Nobili, D., in Semiconductor Silicon: Proceedings of the Sixth International Symposium on Silicon Materials Science and Technology (1990), p. 550.

60. S. Solmi, A. Parisini, R. Angelucci, A. Armigliato, D. Nobili, and L. Moro, Phys. Rev. B 53, 7836 (1996).

61. A.N. Christensen, F. Leccabue, C. Paorici, in Crystal Growth and Characterization of Advanced Materials-Proceedings of the International School on Crystal Growth and Characterization of Advanced Materials (World Scientific Publishing Cp. Pte. Ltd. 1988), p. 315.

62. Siegert Wafer, Resistivity calculator for Silicon, https://www.siege rtwafer.com/calculator.html. Accessed 20 June 2020.

63. J.A. Burton, R.C. Prim, and W.P. Slichter, J. Chem. Phys. 21, 1987 (1953).

64. S. Pizzini, in Physical Chemistry of Semiconductor Materials and Processes, ed. by S. Pizzini (John Wiley \& Sons, 2015), p: 265. 
65. M. Porrini, V.V. Voronkov, and A. Giannattasio, ECS J. Solid State Sci. Technol. 8, 12 (2019).

66. Y. Hu, H. Schøn, E.J. Øvrelid, Ø. Nielsen, and L. Arnberg, AIP Adv. 2, (2012)

67. A. Barz, P. Dold, U. Kerat, S. Recha, K.W. Benz, M. Franz, and K. Pressel, J. Vac. Sci. Technol. B: Microelectron. Nanometer Struct. Process. Meas. Phenom. 16, 1627 (1998).

68. P. Dold, A. Barz, S. Recha, K. Pressel, M. Franz, and K.W. Benz, J. Cryst. Growth 192, 125 (1998).

69. I. Yonenaga, J. Cryst. Growth 275, 91 (2005).

70. R.N. Hall, J. Phys. Chem. 57, 836 (1953).

71. J.A. Burton, Physica 20, 845 (1954).

72. J.A. James and D.H. Richards, Int. J. Electron. 3, 500 (1957).

73. H.R. Huff, T.G. Digges Jr, and O.B. Cecil, J. Appl. Phys. 42, 1235 (1971).
74. J.R. Davis, A. Rohatgi, R.H. Hopkins, P.D. Blais, P. Rai-Choudhury, J.R. Mccormick, and H.C. Mollenkopf, IEEE Trans. Electron. Dev. 27, 677 (1980).

75. B.T. Puchala, Modeling Defect Mediated Dopant Diffusion in Silicon (Doctoral Dissertation, University of Michigan, 2009).

76. K. Sueoka, E. Kamiyama, and J. Vanhellemont, J. Appl. Phys. 114, (2013)

77. S.L. Sihto, J. Slotte, J. Lento, K. Saarinen, E.V. Monakhov, A.Y. Kuznetsov, and B.G. Svensson, Phys. Rev. B 68, (2003).

Publisher's Note Springer Nature remains neutral with regard to jurisdictional claims in published maps and institutional affiliations. 